Article

\title{
Assessment of GPM-IMERG and Other Precipitation Products against Gauge Data under Different Topographic and Climatic Conditions in Iran: Preliminary Results
}

\author{
Ehsan Sharifi ${ }^{1, *}$, Reinhold Steinacker ${ }^{1}$ and Bahram Saghafian ${ }^{2}$ \\ 1 Department of Meteorology and Geophysics, University of Vienna, Vienna 1090, Austria; \\ reinhold.steinacker@univie.ac.at \\ 2 Department of Technical and Engineering, Science and Research Branch, Islamic Azad University, \\ Tehran 1477893855, Iran; b.saghafian@gmail.com \\ * Correspondence: ehsansharifi83@gmail.com; Tel.: +43-676-976-6304
}

Academic Editors: Magaly Koch and Prasad S. Thenkabail

Received: 2 November 2015; Accepted: 2 February 2016; Published: 6 February 2016

\begin{abstract}
The new generation of weather observatory satellites, namely Global Precipitation Measurement (GPM) constellation satellites, is the lead observatory of the 10 highly advanced earth orbiting weather research satellites. Indeed, GPM is the first satellite that has been designed to measure light rain and snowfall, in addition to heavy tropical rainfall. This work compares the final run of the Integrated Multi-satellitE Retrievals for GPM (IMERG) product, the post real time of TRMM and Multi-satellite Precipitation Analysis (TMPA-3B42) and the Era-Interim product from the European Centre for Medium Range Weather Forecasts (ECMWF) against the Iran Meteorological Organization (IMO) daily precipitation measured by the synoptic rain-gauges over four regions with different topography and climate conditions in Iran. Assessment is implemented for a one-year period from March 2014 to February 2015. Overall, in daily scale the results reveal that all three products lead to underestimation but IMERG performs better than other products and underestimates precipitation slightly in all four regions. Based on monthly and seasonal scale, in Guilan all products, in Bushehr and Kermanshah ERA-Interim and in Tehran IMERG and ERA-Interim tend to underestimate. The correlation coefficient between IMERG and the rain-gauge data in daily scale is far superior to that of Era-Interim and TMPA-3B42. On the basis of daily timescale of bias in comparison with the ground data, the IMERG product far outperforms ERA-Interim and 3B42 products. According to the categorical verification technique in this study, IMERG yields better results for detection of precipitation events on the basis of Probability of Detection (POD), Critical Success Index (CSI) and False Alarm Ratio (FAR) in those areas with stratiform and orographic precipitation, such as Tehran and Kermanshah, compared with other satellite/model data sets. In particular, for heavy precipitation ( $>15 \mathrm{~mm} /$ day), IMERG is superior to the other products in all study areas and could be used in future for meteorological and hydrological models, etc.
\end{abstract}

Keywords: GPM constellation satellites; IMERG; TMPA-3B42; ERA-Interim; satellite precipitation estimates; remote sensing; statistical analysis

\section{Introduction}

Water is fundamental to life on Earth. Knowing the locations and extents of rain and snowfall is vital to understanding how weather and climate impact our environment and Earth's water and energy cycles, including effects on agriculture, fresh water availability, and response to natural disasters. Since rainfall and snowfall vary greatly on a small scale and over time, satellites can provide a better picture 
of rain and snow distribution around the globe than the ground instruments, particularly in areas where surface measurements are lacking. Nonetheless, evaluation of satellite precipitation estimates is essential prior to operational use. This is why many previous studies are devoted to the validation of satellite estimation [1-3].

The primary requirement in precipitation measurement is to know where and how much precipitation is falling at any given time. Such precipitation characteristics may be determined through traditional ground-based rain-gauges and/or advanced satellite precipitation products. Another important aspect deals with the duration of precipitation. In this study, accumulation products have been evaluated daily (derived from accumulation of half-hourly and 3-hourly basis for IMERG, TMPA-3B42 respectively), monthly and seasonally as well.

Radar rainfall may also be used to provide an indirect measurement of rainfall, but then the radar systems need to cover large areas and have appropriate radar rainfall relationships according to the type of precipitation. For most developing countries and even more so for lesser developed countries, radar systems remain too expensive and difficult to maintain and, thus, are not a feasible option for this purpose [4]. Furthermore, radar has limited coverage over mountainous areas of terrain, and shading problems as well. Satellite based estimates of rainfall are not as accurate as gauges or radar rainfall, but have the advantage of high temporal resolution and global spatial coverage over oceans and land, particularly mountainous regions and sparsely populated areas. In areas where a sufficiently dense gauge network and radar system is not available, satellite-derived rainfall can be a "critical tool for identifying hazards from smaller-scale rainfall and flood events" [5].

\section{Mission Overview of GPM}

Global Precipitation Measurement (GPM) constellation satellites are an international mission to provide next generation observations of rain and snow. NASA and the Japanese Aerospace Exploration Agency (JAXA) launched the GPM Core Observatory satellite on 27 February 2014, carrying advanced instruments that will set a new standard for precipitation measurements from space. GPM constellation satellites provided by the American National Aeronautics and Space Administration (NASA), the Japanese Aerospace Exploration Agency (JAXA), Eumetsat's MetOp-B and planned MetOp-C, the NASA-NOAA (American National Oceanic and Atmospheric Administration) Suomi National Polar-orbiting, France and India's Megha-Tropiques, NOAA's Polar-orbiting Operational Environmental Satellites, Japan's first Global Change Observation Mission-Water, U.S. Defense Department meteorological satellites and NOAA's Joint Polar Satellite System. The data they provide will be used to unify precipitation measurements made by an international network of partner satellites to quantify when, where, and how much it rains or snows around the world. The GPM Core Observatory satellite flies at an altitude of $407 \mathrm{~km}$ in a non-sun-synchronous orbit and continues the TRMM sampling strategy and will extend the observations to higher latitudes, covering the globe from the Antarctic Circle to the Arctic Circle [6]. However, as you see in Table 1, at present, this version covers a latitude from $60^{\circ} \mathrm{N}$ to $60^{\circ} \mathrm{S}$.

Table 1. Characteristics of Satellite/Model Precipitation Products.

\begin{tabular}{ccccc}
\hline Products & Temporal Resolution & Spatial Resolution & Regions & Availability Period \\
\hline IMERG & half-hourly & 0.1 degree & $60^{\circ} \mathrm{N}-60^{\circ} \mathrm{S}$ & March 2014-present \\
3B42 & 3-hourly & 0.25 degree & $50^{\circ} \mathrm{N}-50^{\circ} \mathrm{S}$ & 1997-April 2015 \\
ERA-INTERIM & daily & 0.125 degree & $90^{\circ} \mathrm{N}-90^{\circ} \mathrm{S}$ & 1979-present \\
\hline
\end{tabular}

The increased sensitivity of the Dual-frequency Precipitation Radar (DPR) and the high-frequency channels on the GPM Microwave Imager (GMI) will enable GPM to improve forecasting by estimating light rain and falling snow outside the tropics, even in the winter seasons, which other satellites are unable to measure [6,7]. 
Researchers and scientists use models for analysis and forecasts of the atmospheric state. The models may have different spatial and temporal resolution. One of the best models, which is used around the world, has been developed by the European Center for Medium Range Weather Forecasts (ECMWF). They have produced a global reanalysis for the last decades of ERA-40 and ERA-Interim, 12-hourly and daily precipitation fields [8]. Moreover, ERA-Interim is the latest global atmospheric reanalysis produced by ECMWF. The ERA-Interim project was conducted in part to prepare a new atmospheric reanalysis to replace ERA-40, which will extend the data to the early part of the twentieth century. Another tool to determine precipitation at relatively fine temporal and spatial scale is satellite observation. During the last decade, many researchers have evaluated and used satellite data sets and some have found that the TMPA-3B42 post real-time product performed better than other products compared with the rain-gauges [9-15]. One of the disadvantages of TMPA-3B42 was the limited area of observation; it covered only the tropical and subtropical belts. Another disadvantage was the ability to estimate heavy rainfall while light rainfall and snowfall were not detected properly [6-12].

As seen in Table 1, IMERG is presently available from mid-March 2014 to the present (with access delay in the order of about three months for the final run version). Based on the preliminary analysis during beta testing by Huffman et al. (2015), IMERG is smoother than 3B43 over oceans and at higher latitudes. This was a goal for IMERG, which provides estimates every half hour, versus the 3-hourly interval for the satellite data contributing to 3B43. Usually, satellite estimation in regions subject to convective precipitation could be difficult whereas they expect that IMERG data sets will be more accurate [7]. Contrary to other satellites, such as TRMM, that could not measure light rain and snowfall, GPM-IMERG uses different sensors from different satellites to detect both light and heavy rain and snowfall. Three critical improvements in GPM are that (1) the orbital inclination has been increased from $35^{\circ}$ to $65^{\circ}$, affording coverage of important additional climate zones; (2) the radar has been upgraded to two frequencies, adding sensitivity to light precipitation; and (3) high-frequency channels (165.5 and $183.3 \mathrm{GHz}$ ) have been added to the passive microwave (PMW) imager, which are expected to facilitate sensing of light and solid precipitation.

In brief, the input precipitation estimates computed from the various satellite passive microwave sensors are inter-calibrated to the GPM Combined Instrument (GCI, using GMI and DPR), because it is presumed to be the best snapshot GPM estimate, then morphed and combined with microwave precipitation-calibrated geosynchronous earth orbit (geo) infrared (IR) fields, and adjusted with monthly surface precipitation gauge analysis data (where available) to provide half-hourly and monthly precipitation estimates. Precipitation phase is diagnosed using analyses of surface temperature, humidity, and pressure. On the other hand, the TMPA combines microwave data from multiple satellites, each inter-calibrated to the TRMM Combined Instrument (TCI), using TRMM Microwave Imager (TMI) and TRMM Precipitation Radar (PR). Coverage gaps in space and time are filled in with calibrated infrared (IR) data (which are generally available with near-global coverage every $3 \mathrm{~h}$ ); coefficients are derived from co-located IR brightness temperatures and the microwave-based precipitation estimates. The final data products reflect scaling the multi-satellite estimates to rain gauge data on a monthly basis, and ensuring that the 3-hourly averages in 3B42 sum to the monthly totals in 3B43 [7].

Other advantages for using satellite precipitation data in places such as Iran include generally insufficient spatial coverage of in-situ data, long delay in data processing and transfer until they become accessible for the public and scientific use, and absence of data sharing in many trans-boundary basins. As a result, this study aims to assess the accuracy of the new generation of satellite precipitation products. To our knowledge, no report exists yet to study the GPM constellation satellites data over Iran.

\section{Recent Works}

The gauges potentially provide in-situ, high time-resolution precipitation measurements at an area of a few square meters and also they have error due to wind, solid precipitation, etc. while the TMI and PR instruments essentially offer instantaneous area-averaged measurements with relatively 
poor time sampling. The measurement errors of both the satellite retrievals and the gauges are not fully understood [16,17]. The comparison of satellite estimates with rain-gauge measurements is often frustrating, because satellites can at best attempt to measure rain amounts over areas many kilometers in size around a gauge, whereas rain-gauges can only record what falls in an area some tens of centimeters in diameter [18]. However, recently released IMERG is going to reduce this sampling issue such that GPM constellation satellites will have improved spatial and temporal resolutions (i.e., $30 \mathrm{~min}$ ).

Many attempts have been made to develop and improve global and regional gridded precipitation gauge data sets in recent years [19-21]. However, due to the lack of observational precipitation datasets over land areas for parts of Asia, Yatagai et al. [22,23] generated a high resolution rain-gauge based daily precipitation grid dataset for the East, Middle East and Russia.

Xie et al. [24] assessed the performance of five satellite-based rainfall outputs by comparison against gauge analysis: TRMM (3B42-V7, 3B42-RT) of US National Weather Service (NWS), Climate Prediction Center (CPC), Morphing Techniques (CMORPH), Precipitation Estimation from Remotely Sensed Information using Artificial Neural Networks (PERSIANN), and those of Naval Research Laboratory (NRL). They found that all satellite products performed better in wet climate regions and wet seasons, but showed limited skills in estimating precipitation over central Asian arid and semi-arid regions.

Renzullo et al. [25] constructed daily precipitation surfaces for Australia from the post real-time TRMM 3B42 rainfall product. This product has been used in stream flow and flood modeling studies where real-time gauge data is sparse [26,27]. Fleming et al. [28] indicated that there is high correlation between TRMM rainfall data and the Australian Bureau of Meteorology monthly grid values data. Regarding the correlation between datasets as a function of climate, the steppe and temperate climate zones show a higher correlation than the tropical and desert zones. The quality of the analysis depends on the density of gauge reports (sparse data imply larger errors), the complexity of the local terrain, i.e., gauges in mountain areas are generally sited in valleys and, therefore, underreport the true areal average rainfall [29].

A strong increase in tropical land precipitation during the past decade is found in ERA-Interim and Global Precipitation Climatology Project 2. While large improvements have been made in terms of temporal homogeneity compared with ERA-40, especially with regard to precipitation, the homogeneity issue still needs to be carefully addressed when interpreting surface flux data from reanalysis or other sources [30].

The performance of GPM satellite-based precipitation has not been studied over arid and semi-arid areas in Iran. To address this, in our research, we compare precipitation estimates of GPM-IMERG-final run data sets with meteorological synoptic stations' data over Iran to evaluate the GPM-based precipitation outputs.

\section{Study Area}

To examine the accuracy of satellite observatory precipitation data in different topographic conditions, we selected four study areas in Iran with diverse topography and within different precipitation zones proposed by Modarres [31] (see Figure 1a,b).

Due to Iran's variable topography and climate conditions, we partitioned the study area to cover provinces such as Kermanshah situated in western Iran. Most of the surface of the province lies within the Zagros Mountains, which forms the western periphery of the Iranian Plateau. Running from southeast to northwest, the nearly parallel broken ridges of the Zagros are highest in the east of the province, and elevation drops progressively towards the west, until the vast plains of Iraq fill the horizon (shown in Figure 1 in zone G5). The climate of the highlands is mild in summer and cold in winter, with heavy snowfall; only the province's western strip belongs to the warm climate. The average temperatures in Kermanshah City are approximately $0{ }^{\circ} \mathrm{C}$ in January and $26{ }^{\circ} \mathrm{C}$ in July. The winds blowing from the Mediterranean Sea carry rainclouds, with an annual precipitation of 
up to $700 \mathrm{~mm}$ in the highlands and about $400 \mathrm{~mm}$ at Kermanshah City [32]. The second province, namely Guilan, belongs to zone G8 and includes the northwestern end of the Alborz Mountains and the western part of the Caspian lowlands of Iran. The mountainous belt is cut through by the deep transversal valley of the Sefidrud. To the northwest, the highlands stretch over a continuous watershed and, except for at their northern end, they are over $2000 \mathrm{~m}$ high, with three spots over $3000 \mathrm{~m}$. Their eastern and northeastern side is deeply carved by parallel streams flowing down towards the Caspian Sea. Prevailing north-south atmospheric currents, humidified over the Caspian, are forced to a vigorous ascent by the mighty barrier of Alborz and thus are responsible for abundant rainfall on both the plain and the northwestern slope of the mountains. Mean annual precipitation varies between $1200 \mathrm{~mm}$ and $1800 \mathrm{~mm}$ along the shoreline, decreases towards a sub-humid area in the southwestern corner of the plain, and reaches again very high amounts in the lower part of the mountain, up to 1500-2400 mm including convective rainfall during summer. Bushehr (shown in Figure 1 in zone G4) is just northwest of the Persian Gulf with an arid and subtropical climate. There are two different regions in Bushehr, which are the plains along the Persian Gulf, and the mountain ranges including the Zagros Mountains. Rainfall in autumn and spring usually occurs in the form of convective precipitation, and during the winter in the form of cyclonic storms. The rest of precipitation is in the form of moderate and light rain. Snowfall was unprecedented in this region. The average annual rainfall in Bushehr is approximately $230 \mathrm{~mm}$ and the average temperatures are approximately $24{ }^{\circ} \mathrm{C}$. Tehran (shown in Figure 1 in zone G2), the capital, at the southern slopes of Alborz Mountains with a semi-arid climate, represents the remaining study area. Tehran's climate is largely defined by its geographic location, with the towering Alborz Mountains to its north and the central desert to the south. It can be generally described as mild in spring and autumn, hot and dry in summer, and cold in winter. The highest point of the Tehran province is Damavand peak at an altitude of $5678 \mathrm{~m}$ and the lower most area of the province being the plains of Varamin, $790 \mathrm{~m}$ above sea level and located to the south-east of the province. The hottest months of the year are from mid-July to mid-September when temperatures average around $28-30{ }^{\circ} \mathrm{C}$ and the coldest months drop to $1^{\circ} \mathrm{C}$ temperature in December to January, and the average annual precipitation is approximately $400 \mathrm{~mm}$, the maximum being during the winter season (see Figure 2a,b).

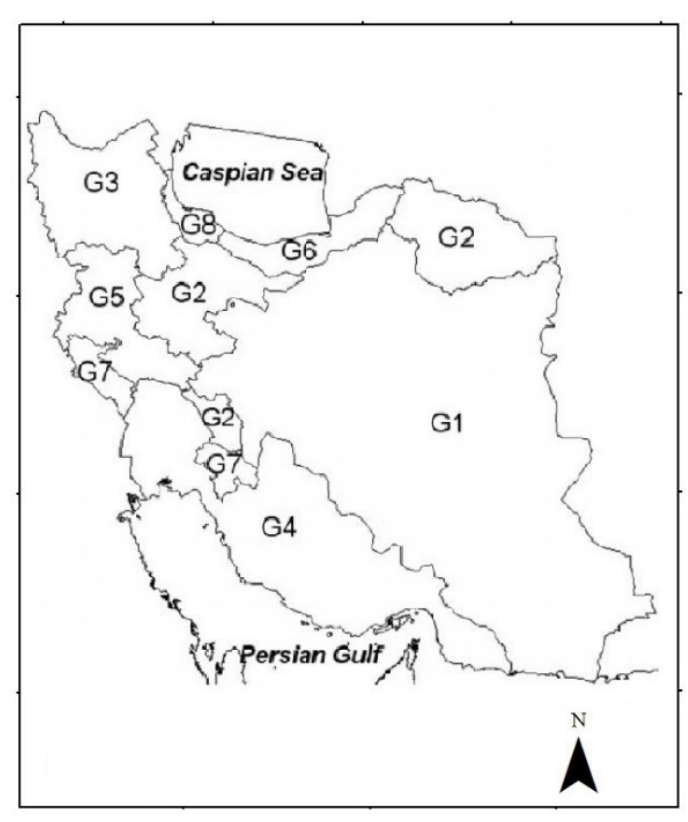

(a)

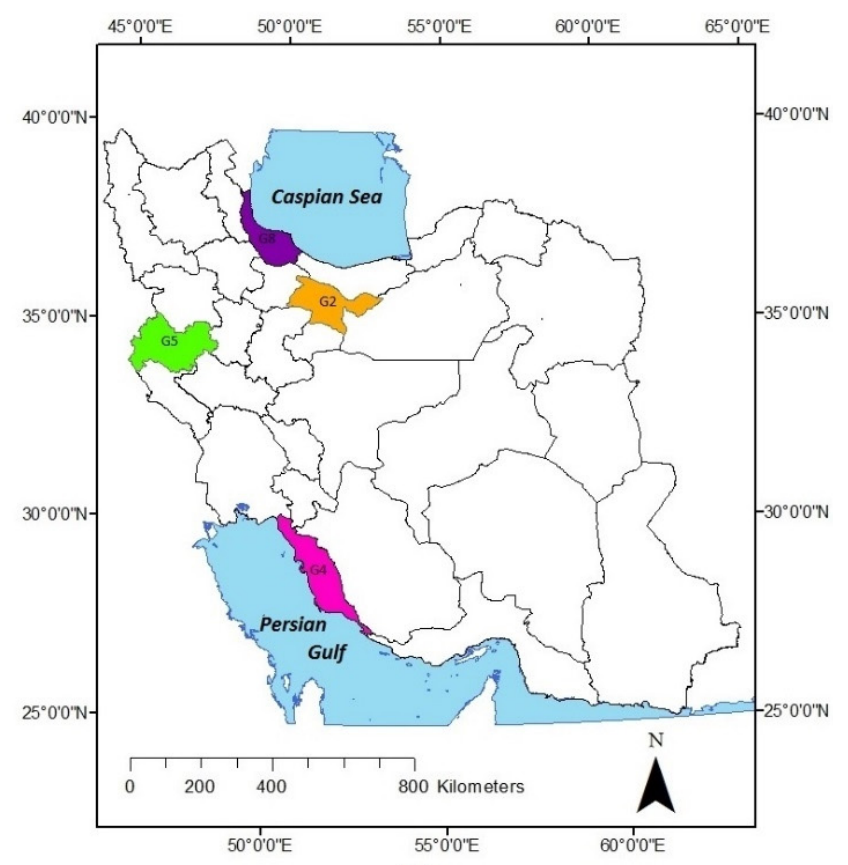

(b)

Figure 1. (a) Spatial distribution of precipitation zones of Iran [31]; and (b) Provincial map of Iran and the four selected study regions. 


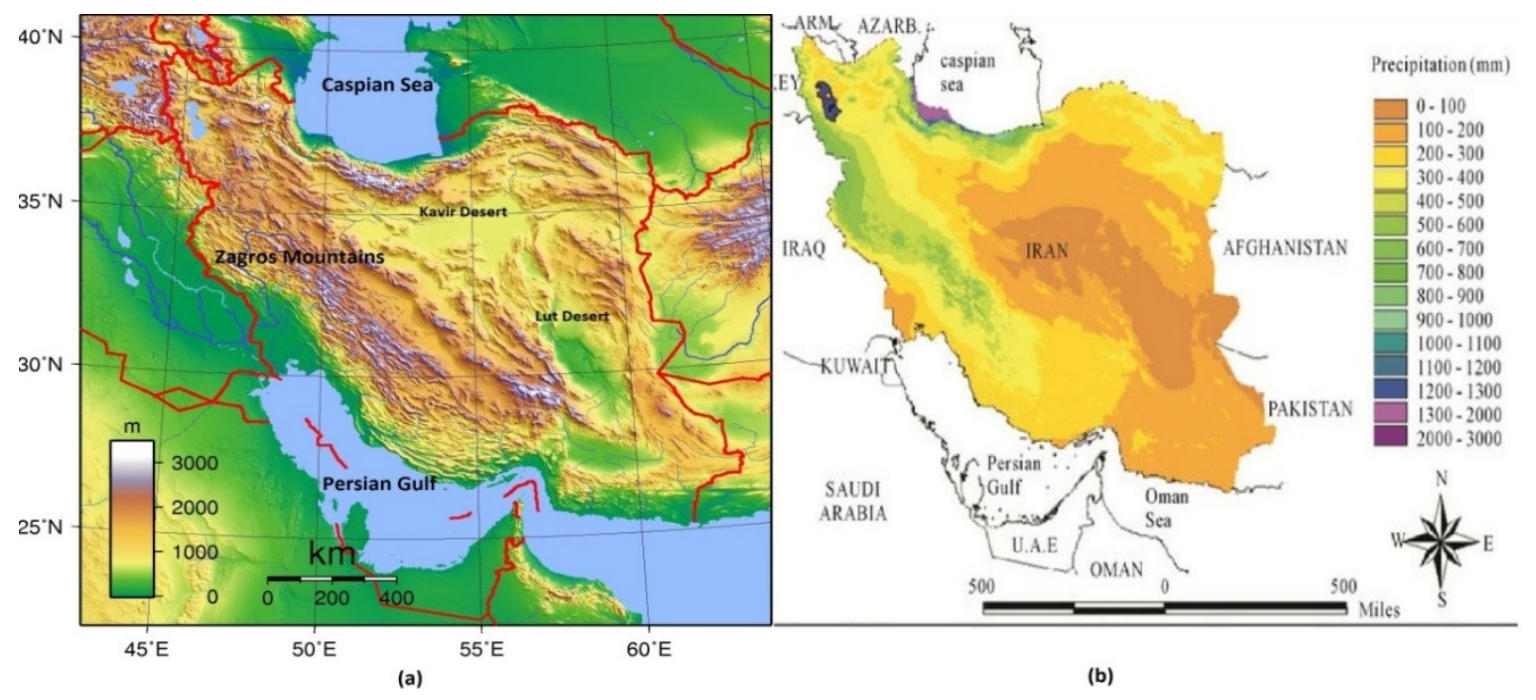

Figure 2. (a) Elevation map of Iran; (b) mean annual precipitation (mm) across Iran, 1961-1990 [11].

\section{Data and Methodology}

\subsection{Data Sources}

In this study, we used only the in-situ meteorological synoptic stations within the four study areas that have undergone quality control by the Iran Meteorological Organization (IMO). However, the stations with large data gaps were removed. The GPM mission's Precipitation Processing System (PPS) at NASA's Goddard Space Flight Center released the IMERG data to the public in late February, 2015. The data set includes precipitation rates since mid-March 2014. Current and future data sets are freely available to users from NASA Goddard Earth Sciences Data and Information Services Center (GES DISC) website [33]. At present, the IMERG data are available from 12 March 2014 to present, thus providing IMERG-V03D data for March 2014 to February 2015 period. The 3B42-V7 from TRMM and other satellites at GES DISC and ERA-Interim data sets from ECMWF [34] are available to the public and are free of charge.

We should mention that further works are needed to evaluate the interannual variation of IMERG data relying on larger samples.

The satellite products were compared with the measured precipitation data of 43 meteorological synoptic stations (Figure 3) at daily, monthly and seasonal time scales for different climate conditions in Iran. At the time of data analysis, we had access only to this number of stations.

In this research, the data of the nearest grid point in the satellite grid (less than 0.05 degrees off the grid points) is compared with that corresponding to the ground point observation (i.e., the meteorological synoptic station). In cases where the grid points were close to the stations, the comparison was carried out directly between them. However, in cases where the ground station was surrounded by four grid cells but not particularly close to none, an average of the four grid points around the station was used as the basis for comparison. Table 1 indicates the characteristics of data sets and Table 2 shows the number of stations and pixels in each area as used in this study. 
Table 2. Number of stations and pixels in each area.

\begin{tabular}{ccccc}
\hline Products & \multicolumn{4}{c}{ Number of Pixels } \\
\hline Study Area & No. of Synoptic Stations & IMERG & $3 B 42$ & ERA-Interim \\
Guilan (G8) & 12 & 23 & 23 & 20 \\
Bushehr (G4) & 9 & 15 & 18 & 12 \\
Kermanshah (G5) & 12 & 24 & 27 & 18 \\
Tehran (G2) & 10 & 16 & 22 & 19 \\
\hline
\end{tabular}

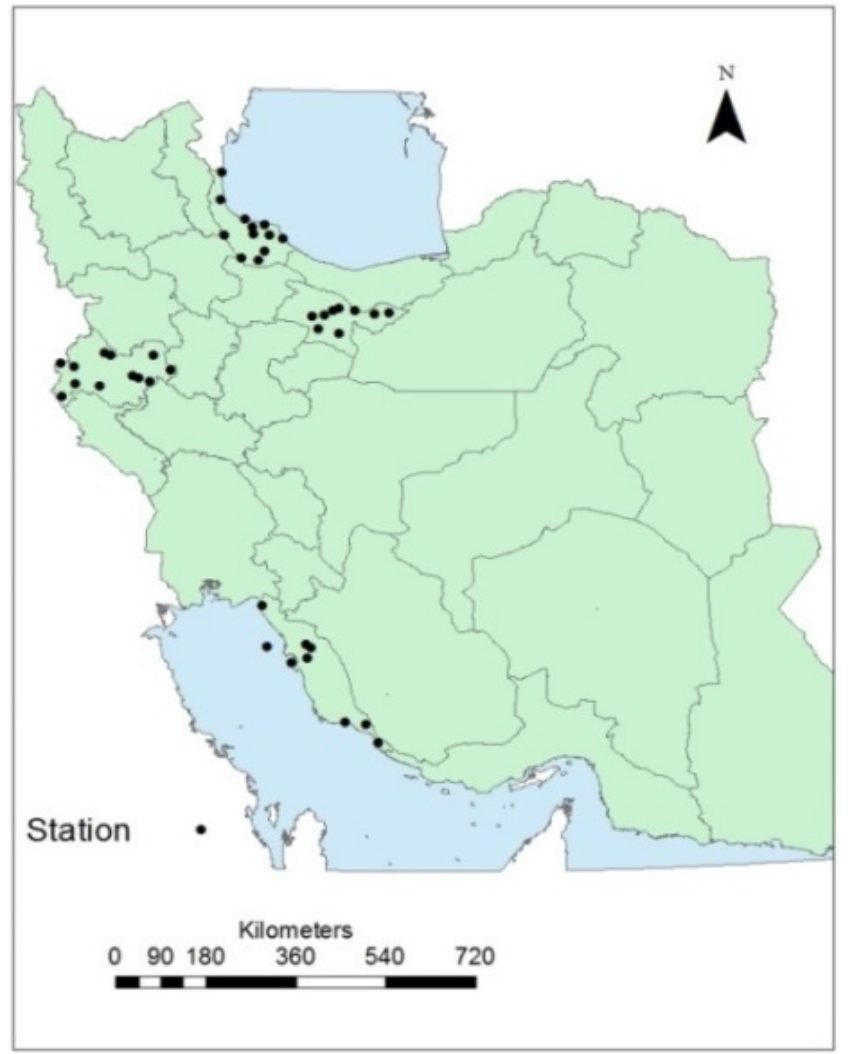

Figure 3. Map of meteorological synoptic stations.

\subsection{Methodology}

\subsubsection{Statistical Analysis}

A comprehensive study was performed on the correlation of IMERG, 3B42, and Era-Interim with the station precipitation data over Iran. In the first step, statistical indices such as bias, multiplicative bias (MBias), relative bias (RBias), mean absolute error (MAE), root mean square error (RMSE), and linear correlation coefficient (CC) were determined. The bias is defined as the average difference between in-situ observations and satellite/model precipitation estimates (S/M-PE), and can be either positive or negative. A negative bias indicates underestimation by satellite precipitation while a positive bias indicates overestimation.

$$
\text { Bias }=\frac{\sum_{i=1}^{N}\left(P_{S_{i}}-P_{O_{i}}\right)}{N}(\mathrm{~mm})
$$

The multiplicative bias (MBias) is the ratio of S/M-PE over rain-gauge value such that a perfect estimation would result in an Mbias of unity. Underestimation will lead to values less than unity, and overestimation to values greater than unity. 


$$
\text { MBias }=\frac{\sum_{i=1}^{N} P_{S_{i}}}{\sum_{i=1}^{N} P_{O_{i}}}
$$

The relative bias (RBias) describes the systematic bias of satellite-based precipitation and behaves the same as bias.

$$
\text { RBias }=\frac{\sum_{i=1}^{N}\left(P_{S_{i}}-P_{O_{i}}\right)}{\sum_{i=1}^{N} P_{O_{i}}} \times 100
$$

The mean absolute error (MAE) is used to represent the average magnitude of the error.

$$
M A E=\frac{\sum_{i=1}^{N}\left|P_{S_{i}}-P_{O_{i}}\right|}{N}(\mathrm{~mm})
$$

The root mean square error (RMSE), which gives a greater weight to the larger errors relative to $\mathrm{MAE}$, is used to measure the average error magnitude.

$$
R M S E=\sqrt{\frac{1}{N} \sum_{i=1}^{N}\left(P_{S_{i}}-P_{O_{i}}\right)^{2}}(\mathrm{~mm})
$$

The correlation coefficient (CC) is used to assess the agreement between satellite/model-based precipitation and rain-gauge observations. The value of $\mathrm{CC}$ is such that $-1<\mathrm{CC}<+1$. A CC value of +1 indicates a perfect positive fit. If there is no linear correlation or a weak linear correlation, $C C$ is close to zero.

$$
C C=\frac{\sum_{i=1}^{N}\left(P_{S_{i}}-\bar{P}_{S}\right)\left(P_{O_{i}}-\bar{P}_{O}\right)}{\sqrt{\sum_{i=1}^{N}\left(P_{S_{i}}-\bar{P}_{S}\right)^{2}} \sqrt{\sum_{i=1}^{N}\left(P_{O_{i}}-\bar{P}_{O}\right)^{2}}}
$$

where $P_{S_{i}}$ is the value of satellite/model precipitation estimates for the $i$ th daily event, $P_{O_{i}}$ is the value of rain-gauge observation for the $i$ th daily event, $N$ is the number of observed days, $\bar{P}_{S}$ is the average value of satellite/model precipitation estimates for $N$ observed days over each pixel or grid points.

\subsubsection{Categorical Technique}

Another assessment technique of satellite estimation/model forecast is using a contingency table that reflects the frequency of "Yes" and "No" of the satellite estimation/forecast model (see Table 3).

Table 3. Contingency table to evaluate precipitation occurrence by satellite products.

\begin{tabular}{lllll}
\hline & & Satellite/Model & & \\
\hline & & Yes & No & total \\
\cline { 3 - 5 } Rain-Gauge & Yes & Hits $(\mathbf{a})$ & Misses $(\mathbf{c})$ & $\mathrm{a}+\mathrm{c}$ \\
& No & False alarms $(\mathbf{b})$ & Correct negative $(\mathrm{d})$ & $\mathrm{b}+\mathrm{d}$ \\
& total & $\mathrm{a}+\mathrm{b}$ & $\mathrm{c}+\mathrm{d}$ & total \\
\hline
\end{tabular}

A dichotomous estimates says, "Yes, an event will happen", or "No, the event will not happen". By using this table for daily precipitation, a set of statistical indices are shown as follows:

Probability of detection (POD) responds to the question of what fraction of the observed "Yes" events was correctly estimated/forecasted. The perfect score is 1 .

$$
P O D=\frac{a}{a+c}
$$

False alarm ratio (FAR) deals with the question of what fraction of the estimated/forecasted "Yes" events did not occur. The ideal score is 0 . 


$$
F A R=\frac{b}{a+b}
$$

Critical success index (CSI) or threat score (TS), answers the question of how well the estimated/forecasted "Yes" events corresponded to the observed "Yes" events. The perfect score is 1.

$$
C S I=\frac{a}{a+b+c}
$$

Accuracy (fraction correct) measures the fraction of correct estimates/forecasts and its perfect score is 1.

$$
\text { Accuracy }=\frac{a+d}{\text { total }}
$$

Bias (frequency bias) answers the question of how the estimated/forecasted frequency of "Yes" events compared to the observed frequency of "Yes" events. Range of values is 0 to $\infty$ with a perfect score of 1.

$$
\text { Bias }=\frac{a+b}{a+c}
$$

Probability of false detection (POFD) deals with the question of what fraction of observed "No" events were incorrectly estimated/forecasted as "Yes". The range varies from 0 to 1 and the perfect score is 0 .

$$
\text { POFD }=\frac{b}{d+b}
$$

Success ratio (SR) responds to the question of what fraction of estimated/forecasted "Yes" events was correctly observed. The range is 0 to 1 and the perfect score is 1 .

$$
S R=\frac{b}{a+b}
$$

Equitable threat score (ETS) or Gilbert skill score, answers the question of how well the estimated/forecasted "Yes" events corresponded to the observed "Yes" events. The range is $-1 / 3$ to 1 and the perfect score is 1 . For rare events, the minimum ETS value is near 0, while the absolute minimum is obtained if the event has a climatological frequency of 0.5 , and there are no hits. If the score goes below 0 then the chance forecast is preferred to the actual forecast, and the forecast is said to be unskilled.

$$
E T S=\frac{a-a_{\text {random }}}{a+b+c-a_{\text {random }}}
$$

Odds ratio (OR) deals with the ratio of the odds of "yes" estimates/forecasts being correct over the odds of "Yes" estimates/forecasts being wrong. Odds ratio range is 0 to $\infty, 0$ indicates no skill and the perfect score is $\infty$.

$$
O R=\frac{a * d}{c * b}
$$

Hanssen and Kuiper discriminant (HK) or true skill statistic (TSS) covers the question of how well the estimates/forecast separated the "Yes" events from the "No" events. The range is -1 to 1 , while 0 indicates no skill and 1 is the perfect score [35-37].

$$
\begin{gathered}
\text { TSS }==\frac{a}{a+c}-\frac{b}{b+d} \\
\text { ORSS }=\frac{a * d-c * b}{a * d+c * b}
\end{gathered}
$$

where $\boldsymbol{a}$ represents the number of times that observed rain is correctly detected, $\boldsymbol{b}$ is the number of times that rain is detected but not observed, $c$ is the number of times that observed rain is not detected, $d$ is the number of times that observed and estimated did not occur and total is the sample size and 


$$
a_{\text {random }}=\frac{(a+c) *(a+b)}{\text { total }}
$$

\section{Results and Discussion}

This Study for the first time has evaluated daily, monthly and seasonally precipitation estimates (derived from half-hourly precipitation estimates of GPM constellation satellites (IMERG) and 3-hourly precipitation estimates of TRMM and multi satellite precipitation analysis (3B42)) and ERA-Interim precipitation fields from ECMWF in comparison with the corresponding rain-gauge observations according to four different topographic and climatic conditions over parts of Iran. The evaluation results follow.

\subsection{Daily Evaluation}

We start with the evaluation of daily IMERG, TMPA-3B42 and ERA-Interim data against rain-gauge observations. This is based on days with observed precipitation solely. Figures 4-6 and Figure 7a-c show the scatter plots of average daily precipitation values during March 2014 to February 2015 in four regions. In Figure 4 and Table 4, all three satellite/model products indicate underestimation according to Bias, Mbias and Rbias values but IMERG shows slight underestimation which means that all three products generate negative systematic errors. 3B42 and ERA-Interim heavily underestimate precipitation in the Guilan region (G8) with respect to Mbias and Rbias. This is more so when the precipitation is above $20 \mathrm{~mm}$ according to Figure 4c for ERA-Interim. On the basis of RMSE and MAE, ERA-Interim shows better results in comparison with the IMERG and 3B42.

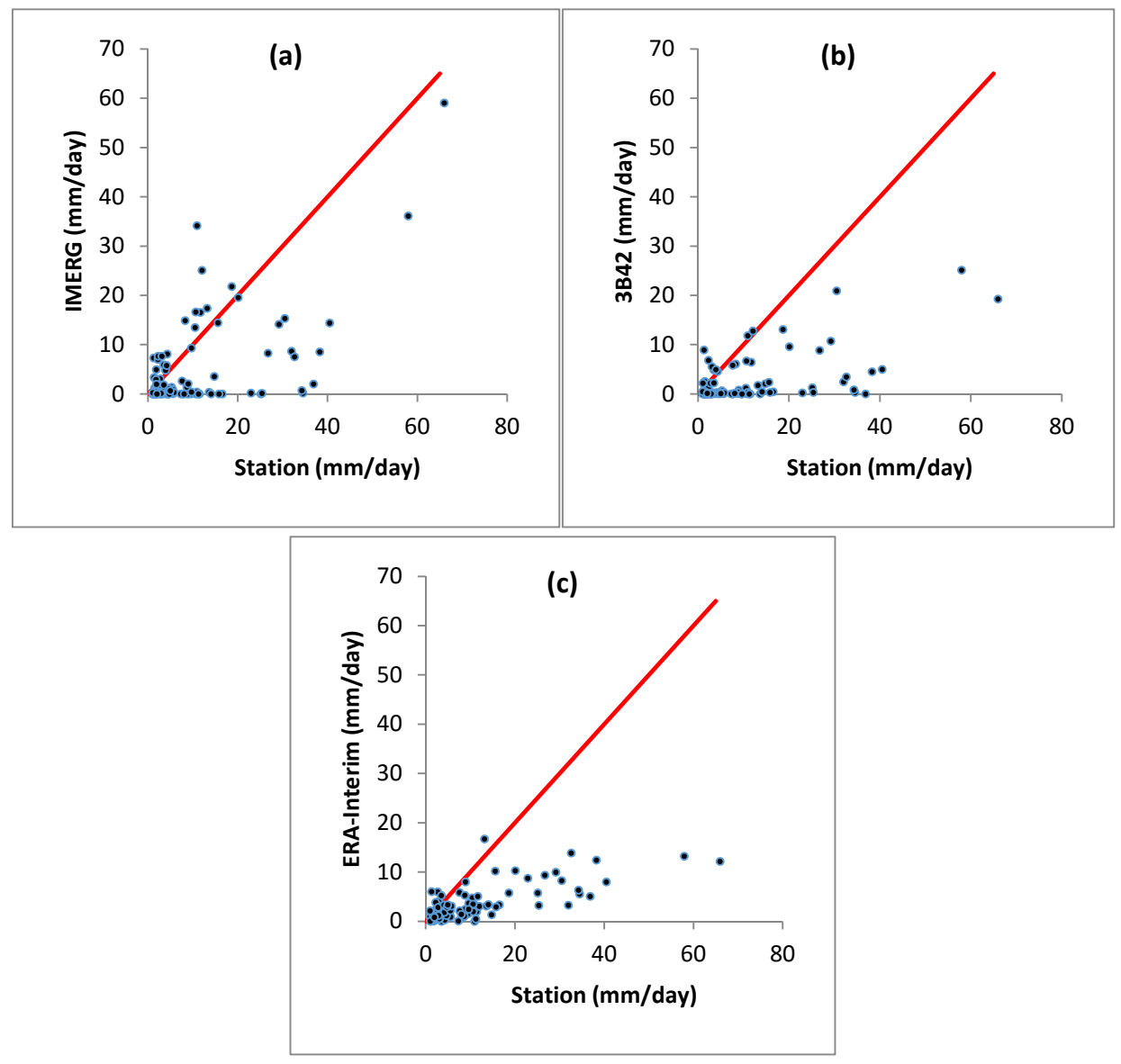

Figure 4. Daily precipitation events scatter plots for Guilan of IMERG (a); 3B42 (b) and ERA-Interim (c) against gauge data (mid-March 2014 to February 2015). 


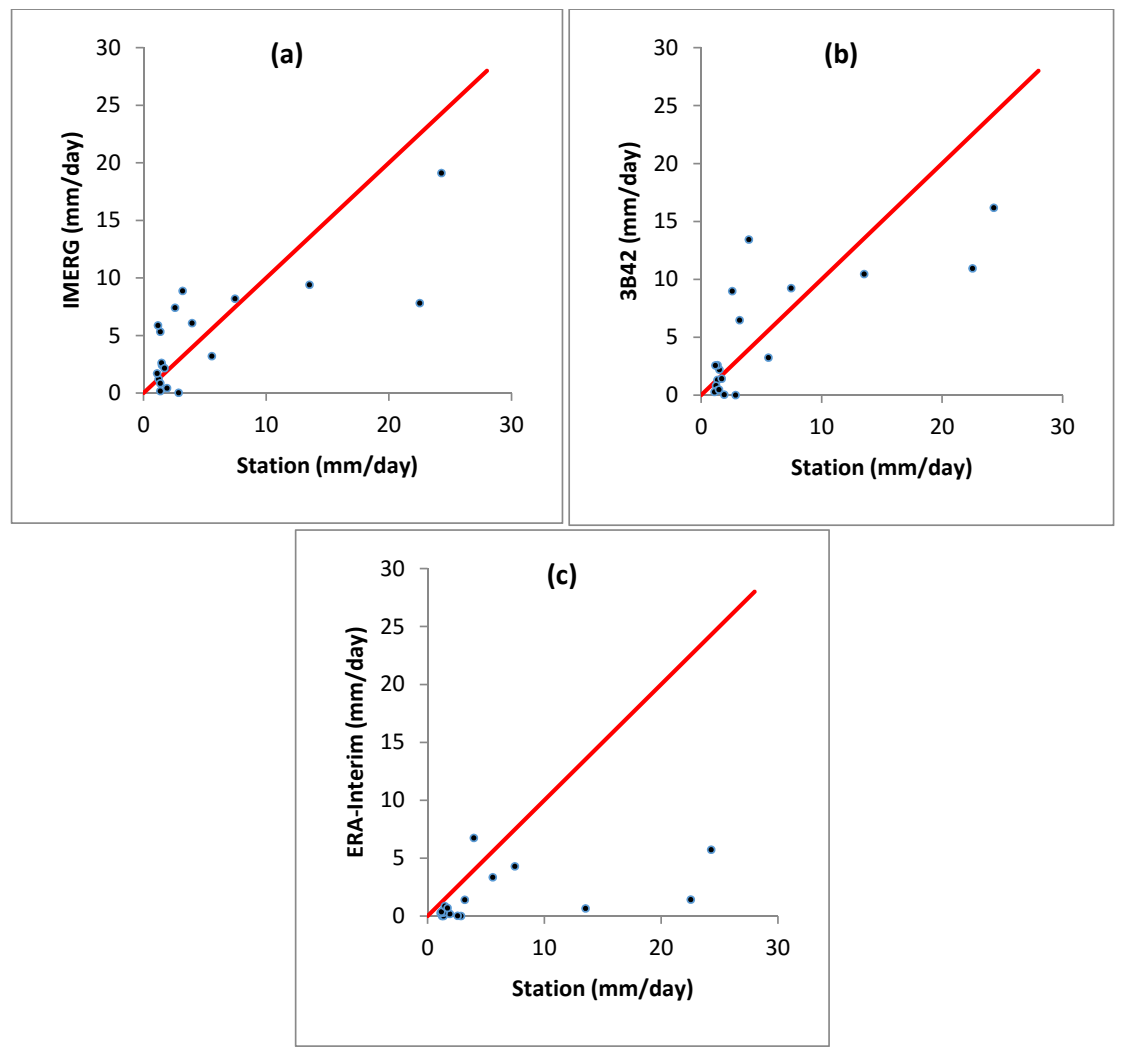

Figure 5. Daily precipitation events scatter plots for Bushehr of IMERG (a); 3B42 (b) and ERA-Interim (c) against gauge data (mid-March 2014 to February 2015).

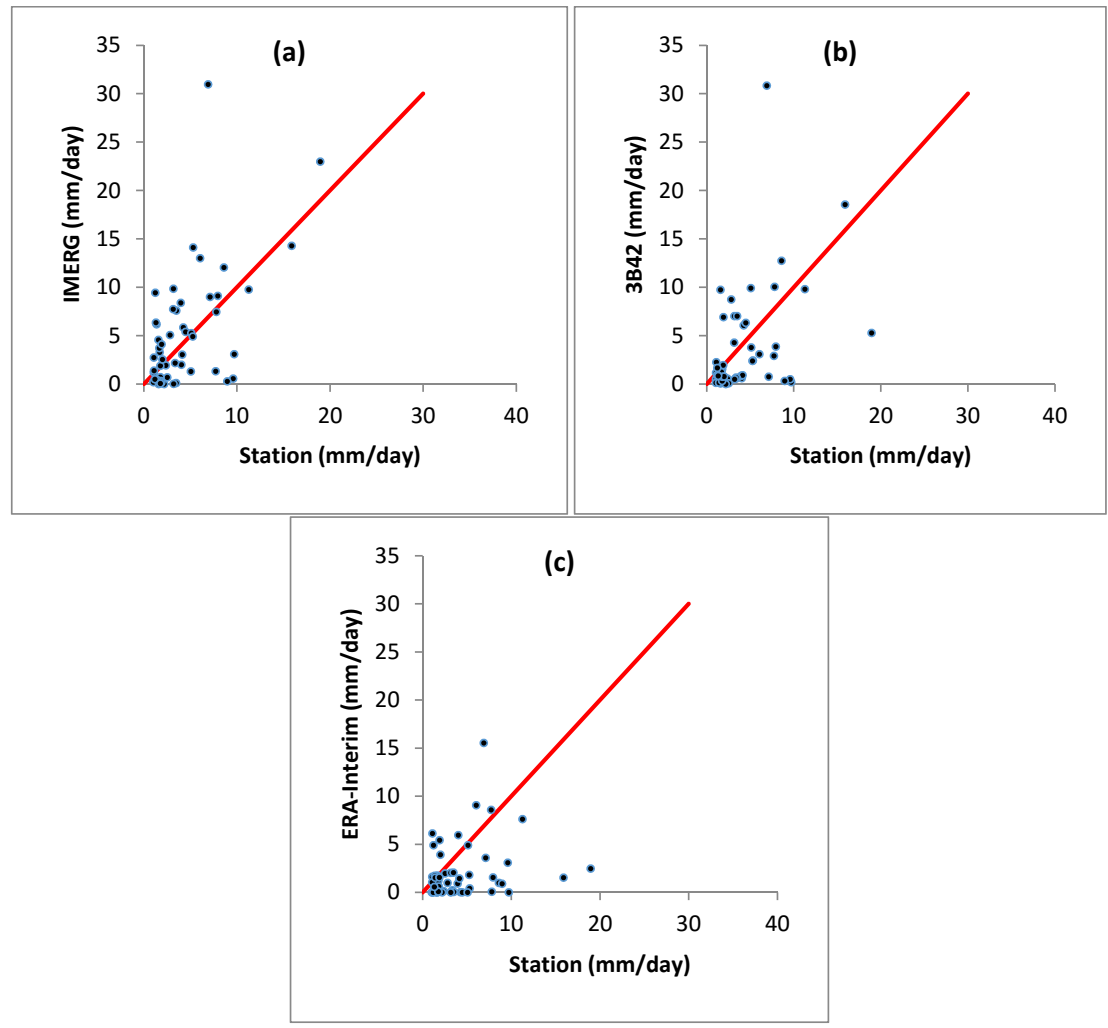

Figure 6. Daily precipitation events scatter plots for Kermanshah of IMERG (a); $3 B 42$ (b) and ERA-Interim (c) against gauge data (mid-March 2014 to February 2015). 


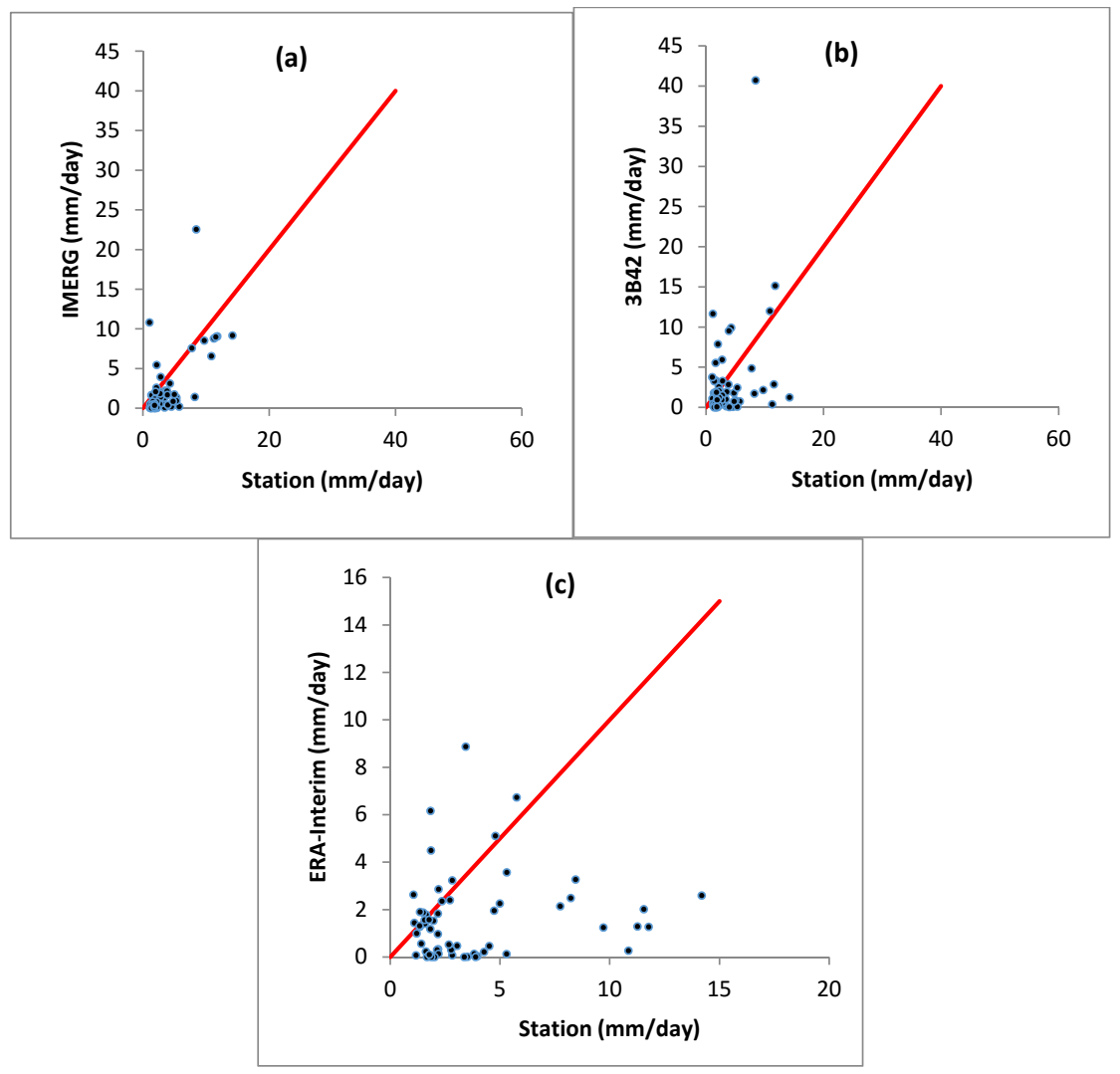

Figure 7. Daily precipitation events scatter plots for Tehran of IMERG (a); 3B42 (b) and ERA-Interim (c) against gauge data (mid-March 2014 to February 2015).

Table 4. Statistical indices of daily precipitation events in Guilan area (mid-March 2014 to February 2015).

\begin{tabular}{cccccccc}
\hline & No. of Events & RMSE $(\mathbf{m m})$ & MAE $(\mathbf{m m})$ & Bias $(\mathbf{m m})$ & Mbias & Rbias & CC \\
\hline IMERG & & 19.41 & 11.59 & $-\mathbf{6 . 4 1}$ & $\mathbf{0 . 6 2}$ & $-\mathbf{0 . 3 7}$ & 0.40 \\
3B42 & \multirow{2}{*}{105} & 19.59 & 11.68 & -9.75 & 0.31 & -0.69 & 0.29 \\
ERA-Interim & & $\mathbf{1 7 . 5 9}$ & $\mathbf{9 . 8 8}$ & -9.06 & 0.35 & -0.65 & $\mathbf{0 . 5 5}$ \\
\hline
\end{tabular}

As seen in Figure 5 and Table 5, IMERG, 3B42 and ERA-Interim tend to underestimate while ERA-Interim underestimates heavily when precipitation is above $10 \mathrm{~mm}$ in Bushehr (G4). The IMERG yields Bias, Mbias and Rbias better than other products. On the other hand, ERA-Interim provides better values of RMSE and MAE in comparison with 3B42 and IMERG. In all, IMERG indicates a good agreement with the observed data.

Table 5. Statistical indices of daily precipitation events in Bushehr area (mid-March 2014 to February 2015).

\begin{tabular}{cccccccc}
\hline & No. of Events & RMSE $(\mathbf{m m})$ & MAE $(\mathbf{m m})$ & Bias $(\mathbf{m m})$ & Mbias & Rbias & CC \\
\hline IMERG & \multirow{2}{*}{19} & 13.7 & 7.92 & $-\mathbf{2 . 5 2}$ & $\mathbf{0 . 9 0}$ & $-\mathbf{0 . 1 0}$ & $\mathbf{0 . 5 1}$ \\
3B42 & $\mathbf{1 1 . 8 6}$ & 7.07 & -2.95 & 0.75 & -0.25 & 0.47 \\
ERA-Interim & & 14.30 & 8.04 & -7.72 & 0.22 & -0.78 & 0.40 \\
\hline
\end{tabular}

Figure 6 presents the scatter plot of daily precipitation over Kermanshah area (G5) where IMERG, 3B42 and ERA-Interim underestimate the observed values. As seen in Table 6, IMERG has a better 
value for RMSE, Bias, Mbias, Rbias and CC in comparison with other data sets while IMERG performs better when precipitation is greater than $10 \mathrm{~mm}$.

Table 6. Statistical indices of daily precipitation events in Kermanshah area (mid-March 2014 to February 2015).

\begin{tabular}{cccccccc}
\hline & No. of Events & RMSE $(\mathbf{m m})$ & MAE $(\mathbf{m m})$ & Bias $(\mathbf{m m})$ & Mbias & Rbias & CC \\
\hline IMERG & \multirow{2}{*}{53} & $\mathbf{7 . 1 0}$ & 4.91 & $-\mathbf{0 . 7 2}$ & $\mathbf{0 . 8 8}$ & $-\mathbf{0 . 1 2}$ & $\mathbf{0 . 5 2}$ \\
3B42 & 7.72 & 5.39 & -1.59 & 0.75 & -0.25 & 0.42 \\
ERA-Interim & & 7.35 & $\mathbf{4 . 3 1}$ & -3.33 & 0.52 & -0.48 & 0.38 \\
\hline
\end{tabular}

As seen in Figure 7, for, IMERG, 3B42 and Era-Interim underestimate Tehran (G2) daily precipitation. Furthermore, based on Table 7,3B42 and IMERG show lower bias and better value of Mbias and Rbias in comparison with the other two datasets whereas ERA-Interim yields better in RMSE and MAE.

Table 7. Statistical indices of daily precipitation events in Tehran area (mid-March 2014 to February 2015).

\begin{tabular}{cccccccc}
\hline & No. of Events & RMSE $(\mathbf{m m})$ & MAE $(\mathbf{m m})$ & Bias $(\mathbf{m m})$ & Mbias & Rbias & CC \\
\hline IMERG & & 6.38 & 4.42 & -1.86 & 0.75 & -0.25 & $\mathbf{0 . 4 6}$ \\
3B42 & \multirow{2}{*}{59} & 7.64 & 7.74 & $-\mathbf{1 . 4 7}$ & $\mathbf{0 . 7 8}$ & $-\mathbf{0 . 2 2}$ & 0.27 \\
ERA-Interim & & $\mathbf{5 . 9 2}$ & $\mathbf{4 . 0 5}$ & -3.42 & 0.35 & -0.65 & 0.14 \\
\hline
\end{tabular}

\subsection{Monthly Evaluation}

To evaluate monthly precipitation, we derived IMERG from half-hourly, 3B42 from 3-hourly and ERA-Interim from daily precipitation. As a reference we compared rain-gauge observations with their corresponding grid points on satellites and models for all days of the corresponding months. Figure 8 and Table 8 show underestimation for monthly scale in all three products but very slightly for IMERG with Bias, Rbias and Mbias of $-29.18 \mathrm{~mm}, 0.98$ and -0.02 , respectively, which shows a better result in comparison with the other two products. Also, IMERG yields MAE and RMSE of $52.75 \mathrm{~mm}$ and $81.43 \mathrm{~mm}$, respectively, in comparison to $59 \mathrm{~mm}$ and $102.76 \mathrm{~mm}$ for $3 \mathrm{~B} 42$ while the same for ERA-Interim are $62.18 \mathrm{~mm}$ and $95.41 \mathrm{~mm}$. On the other hand, CC of ERA-Interim indicates better agreement than others in the Guilan region.

As seen in Figure 9 and Table 9, IMERG and 3B42 tend to overestimate while ERA-Interim underestimates in Bushehr. The 3B42 yields for all indices better results than the other two data sets while ERA-Interim shows significant agreement with a correlation coefficient of 0.95 .

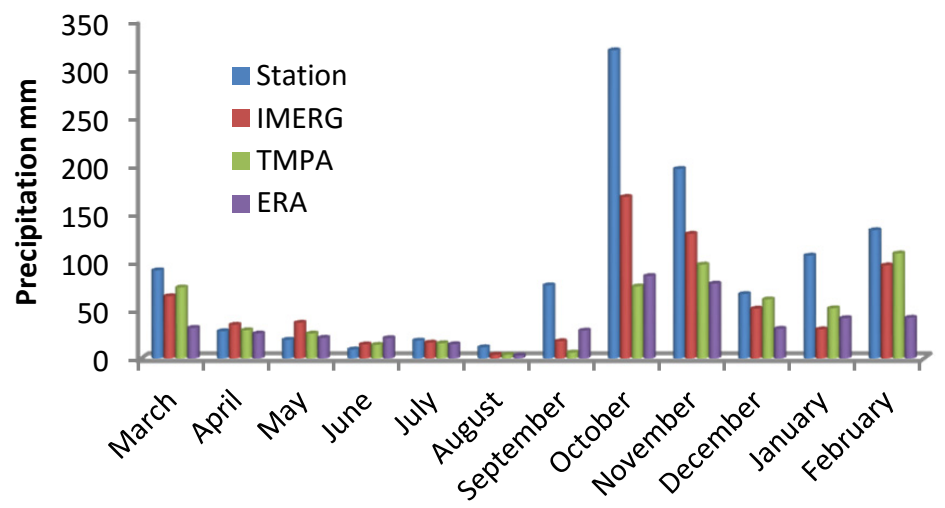

Figure 8. Guilan monthly precipitation (mid-March 2014 to February 2015). 
Table 8. Statistical indices of monthly precipitation in Guilan area (mid-March 2014 to February 2015).

\begin{tabular}{cccc}
\hline & IMERG & TMPA & ERA-Interim \\
\hline RMSE $(\mathbf{m m})$ & $\mathbf{8 1 . 4 3}$ & 102.76 & 95.41 \\
MAE $(\mathbf{m m})$ & $\mathbf{5 2 . 7 5}$ & 59.00 & 62.18 \\
Bias $(\mathbf{m m})$ & $-\mathbf{2 9 . 1 8}$ & -35.57 & -54.47 \\
Mbias & $\mathbf{0 . 9 8}$ & 0.93 & 0.58 \\
Rbias & $\mathbf{- 0 . 0 2}$ & -0.07 & -0.42 \\
CC & 0.76 & 0.52 & $\mathbf{0 . 8 5}$ \\
\hline
\end{tabular}

Table 9. Statistical indices of monthly precipitation in Bushehr area (mid-March 2014 to February 2015).

\begin{tabular}{cccc}
\hline & IMERG & 3B42 & ERA-Interim \\
\hline RMSE $(\mathbf{m m})$ & 14.36 & $\mathbf{1 1 . 8 8}$ & 16.50 \\
MAE $(\mathbf{m m})$ & 7.13 & $\mathbf{6 . 3 1}$ & 6.39 \\
\hline Bias $(\mathbf{m m})$ & 3.84 & $\mathbf{1 . 0 5}$ & -5.86 \\
Mbias & 1.49 & $\mathbf{1 . 2 1}$ & 0.39 \\
\hline Rbias & 0.71 & $\mathbf{0 . 2 1}$ & -0.61 \\
CC & 0.82 & 0.89 & $\mathbf{0 . 9 5}$ \\
\hline
\end{tabular}

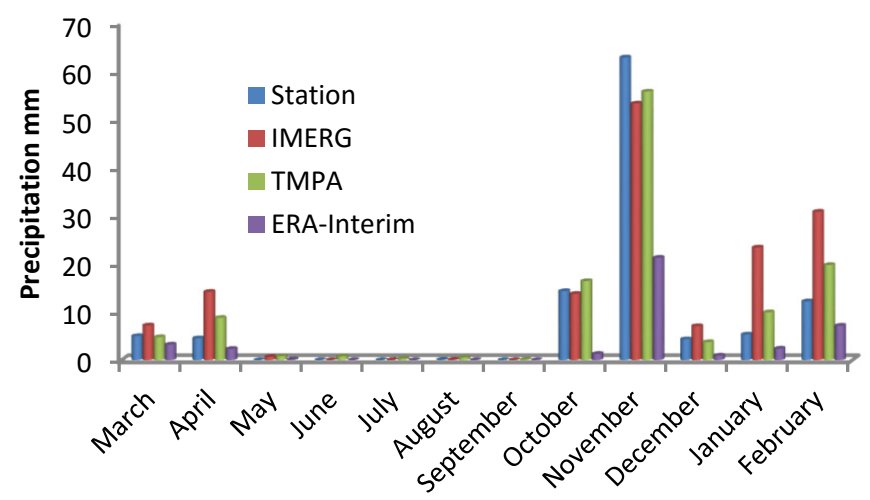

Figure 9. Bushehr monthly precipitation (mid-March 2014 to February 2015).

Regarding to monthly precipitation over the Kermanshah area, based on Figure 10 and Table 10, IMERG and 3B42 overestimate and ERA-Interim underestimates the observed values. 3B42 presents lower Bias, MAE and RMSE in comparison with the other two data sets. Furthermore, based on Figure 10, ERA-Interim shows a very slight bias during the January, February and March (winter season).

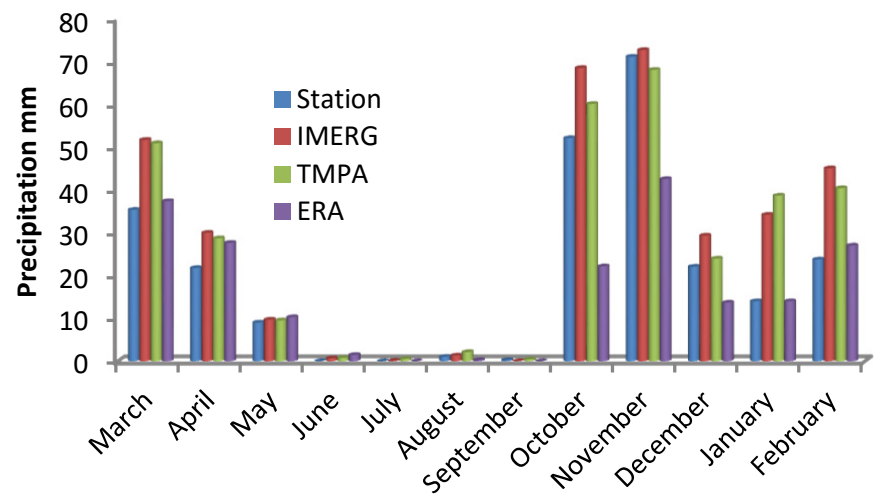

Figure 10. Kermanshah monthly precipitation (mid-March 2014 to February 2015). 
Table 10. Statistical indices of monthly precipitation in Kermanshah area (mid-March 2014 to February 2015).

\begin{tabular}{cccc}
\hline & IMERG & 3B42 & ERA-Interim \\
\hline RMSE (mm) & 16.94 & $\mathbf{1 5 . 6 4}$ & 16.87 \\
MAE (mm) & 11.50 & $\mathbf{1 0 . 3 1}$ & 10.34 \\
Bias (mm) & 7.70 & $\mathbf{4 . 5 6}$ & -5.67 \\
Mbias & 1.62 & 1.40 & $\mathbf{0 . 8 2}$ \\
Rbias & 0.62 & 0.57 & $-\mathbf{0 . 1 8}$ \\
CC & $\mathbf{0 . 8 8}$ & 0.85 & 0.84 \\
\hline
\end{tabular}

As seen in Figure 11 and Table 11, 3B42 tends to overestimate Tehran monthly precipitation whereas IMERG and ERA-Interim tend to underestimate. IMERG shows strong overestimates during October while ERA-Interim is almost unbiased in this month. Generally, IMERG represents better value of Bias, Mbias and Rbias while Era-Interim yields a better value for RMSE and MAE.

Table 11. Statistical indices of monthly precipitation in Tehran area (mid-March 2014 to February 2015).

\begin{tabular}{cccc}
\hline & IMERG & 3B42 & ERA-Interim \\
\hline RMSE (mm) & 19.88 & 20.61 & $\mathbf{1 4 . 7 4}$ \\
MAE (mm) & 14.08 & 14.55 & $\mathbf{1 1 . 0 8}$ \\
Bias (mm) & $-\mathbf{5 . 1 4}$ & 11.56 & -7.34 \\
Mbias & $\mathbf{1 . 1 3}$ & 2.03 & 0.82 \\
Rbias & $\mathbf{0 . 1 3}$ & 1.03 & -0.18 \\
CC & 0.57 & 0.69 & $\mathbf{0 . 8 0}$ \\
\hline
\end{tabular}

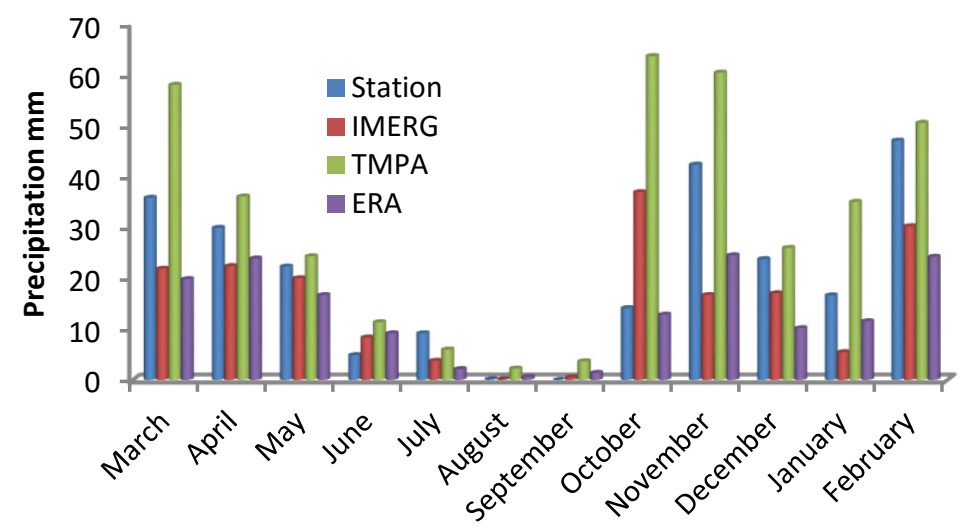

Figure 11. Tehran monthly precipitation (mid-March 2014 to February 2015).

\subsection{Seasonal Evaluation}

To evaluate the seasonal precipitation rain-gauge observations with their corresponding grid points on satellites and models, all days of the corresponding seasons are compared. Based on seasonal scale, Figure 12 and Table 12 indicate that all three products tend to underestimate in all seasons except spring in the Guilan region. IMERG has a better value of Bias, RMSE, Mbias and Rbias while ERA-Interim represents significant agreement.

With respect to Figure 13 and Table 13, 3B42 shows the best results in Bushehr in comparison with other data sets. IMERG and 3B42 displayed overestimates and ERA-Interim underestimates.

As seen in Figure 14 and Table 14, 3B42 and IMERG tend to overestimate while ERA-Interim underestimates in the Kermanshah region. The IMERG yields a correlation coefficient of 0.95 which is a good agreement between satellite estimation and rain-gauge observation and there is no great 
difference for MAE and Bias among all data sets. In all, ERA-Interim indicates a strong bias during autumn and a slight bias during winter.

Table 12. Statistical indices of seasonal precipitation in Guilan area.

\begin{tabular}{cccc}
\hline & IMERG & $\mathbf{3 B 4 2}$ & ERA-Interim \\
\hline RMSE (mm) & $\mathbf{2 0 6 . 1 1}$ & 232.06 & 237.99 \\
MAE (mm) & 162.68 & $\mathbf{1 5 7 . 2 8}$ & 179.10 \\
Bias (mm) & $-\mathbf{9 7 . 8 8}$ & -106.72 & -163.03 \\
Mbias & $\mathbf{0 . 9 6}$ & 0.93 & 0.58 \\
Rbias & $-\mathbf{0 . 0 4}$ & -0.07 & -0.42 \\
CC & 0.85 & 0.75 & $\mathbf{0 . 9 3}$ \\
\hline
\end{tabular}

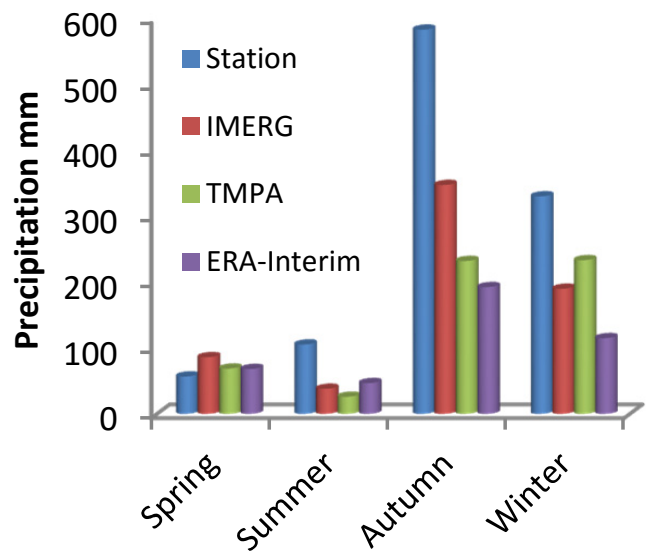

Figure 12. Guilan seasonal precipitation.

Table 13. Statistical indices of seasonal precipitation in Bushehr area.

\begin{tabular}{cccc}
\hline & IMERG & 3B42 & ERA-Interim \\
\hline RMSE (mm) & 30.37 & $\mathbf{1 7 . 8 1}$ & 30.12 \\
MAE (mm) & 22.74 & $\mathbf{1 3 . 5 8}$ & 17.99 \\
Bias (mm) & 10.46 & $\mathbf{3 . 1 4}$ & -17.59 \\
Mbias & 1.60 & $\mathbf{1 . 2 1}$ & 0.39 \\
Rbias & 0.60 & $\mathbf{0 . 2 1}$ & -0.61 \\
CC & 0.83 & $\mathbf{0 . 9 5}$ & 0.92 \\
\hline
\end{tabular}

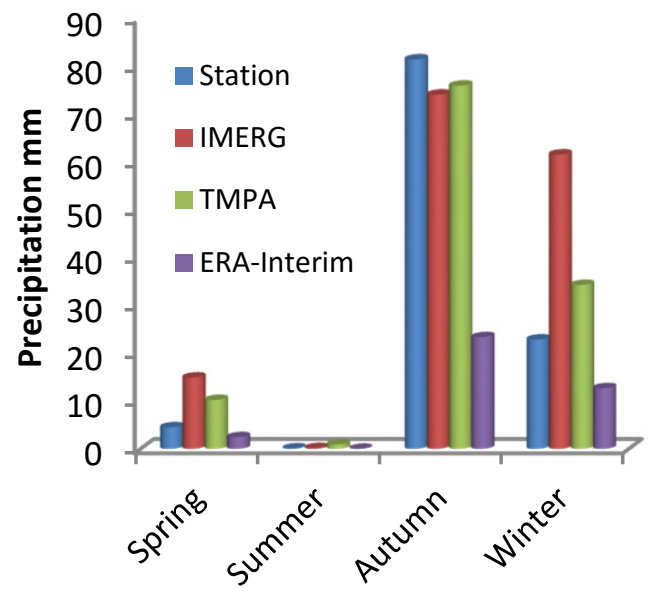

Figure 13. Bushehr seasonal precipitation. 
Table 14. Statistical indices of seasonal precipitation in Kermanshah area.

\begin{tabular}{cccc}
\hline & IMERG & 3B42 & ERA-Interim \\
\hline RMSE (mm) & $\mathbf{3 4 . 7 3}$ & 36.36 & 39.43 \\
MAE (mm) & 27.52 & $\mathbf{2 6 . 6 9}$ & 28.00 \\
Bias (mm) & 17.87 & 18.26 & $\mathbf{- 1 7 . 0 2}$ \\
Mbias & 1.45 & 1.56 & $\mathbf{0 . 8 2}$ \\
Rbias & 0.64 & 0.56 & $\mathbf{- 0 . 1 8}$ \\
CC & $\mathbf{0 . 9 5}$ & 0.92 & 0.88 \\
\hline
\end{tabular}

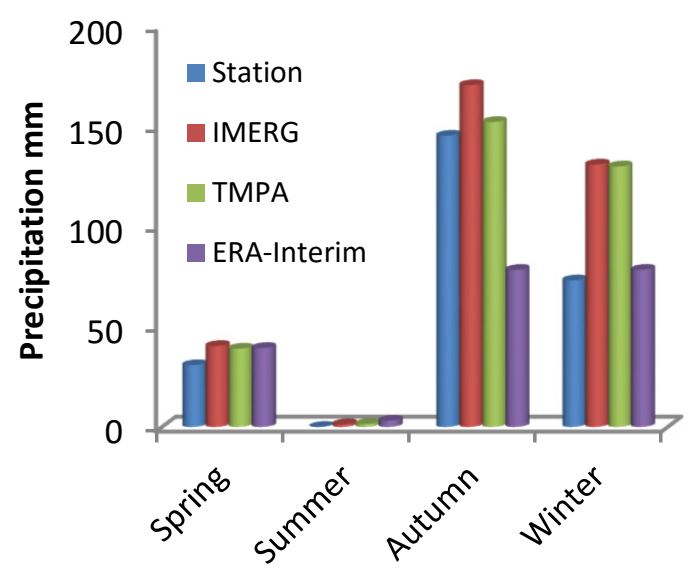

Figure 14. Kermanshah seasonal precipitation.

IMERG and ERA-Interim displayed underestimation and 3B42 overestimation over Tehran region. Among these products, IMERG has better results in comparison with the other data sets while ERA-Interim yields a smaller magnitude of error (Figure 15 and Table 15).

Table 15. Statistical indices of seasonal precipitation in Tehran area.

\begin{tabular}{cccc}
\hline & IMERG & 3B42 & ERA-Interim \\
\hline RMSE $(\mathbf{m m})$ & 43.68 & 46.48 & $\mathbf{3 3 . 1 8}$ \\
MAE $(\mathbf{m m})$ & 34.54 & 35.57 & $\mathbf{2 7 . 5 4}$ \\
Bias $(\mathbf{m m})$ & $-\mathbf{1 5 . 4 2}$ & 34.67 & -22.01 \\
Mbias & $\mathbf{1 . 1 3}$ & 2.03 & 0.82 \\
Rbias & $\mathbf{0 . 1 3}$ & 1.03 & -0.18 \\
CC & 0.84 & $\mathbf{0 . 9 3}$ & 0.90 \\
\hline
\end{tabular}

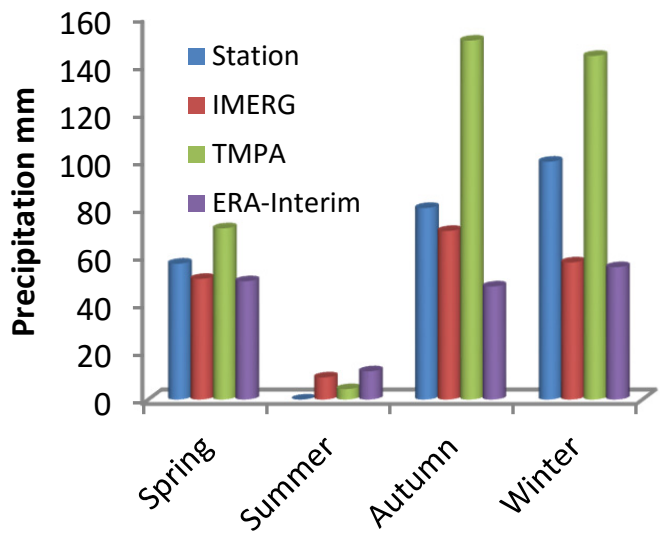

Figure 15. Tehran seasonal precipitation. 


\subsection{Evaluation of Dichotomous Estimates/Forecasts}

With respect to an evaluation through contingency tables, Figure 16a-c and Table 16 reveals higher POD (0.74), lower FAR (0.40) and higher CSI (0.49) by ERA-Interim over the North of Iran, Guilan area, compared to other satellite products. High POD may have been influenced by the dominance of convective storms [38]. Lower POD for 3B42 and IMERG may be associated with missed precipitation over this region.

Table 16. Spatially averaged POD, FAR and CSI metrics.

\begin{tabular}{cccccccccccc}
\hline & & \multicolumn{3}{c}{ POD } & & & FAR & & \multicolumn{1}{c}{ CSI } \\
& $\begin{array}{c}\text { Number of } \\
\text { Daily Events }\end{array}$ & IMERG & $\mathbf{3 B 4 2}$ & ERA & IMERG & $\mathbf{3 B 4 2}$ & ERA & IMERG & 3B42 & ERA \\
\hline Guilan (G8) & $\mathbf{1 0 5}$ & 0.46 & 0.39 & $\mathbf{0 . 7 4}$ & 0.52 & 0.59 & $\mathbf{0 . 4 0}$ & 0.29 & 0.23 & $\mathbf{0 . 4 9}$ \\
\hline Bushehr (G4) & $\mathbf{1 9}$ & $\mathbf{0 . 7 0}$ & 0.56 & 0.39 & 0.59 & 0.55 & $\mathbf{0 . 5 4}$ & $\mathbf{0 . 3 5}$ & 0.33 & 0.28 \\
\hline Kermanshah (G5) & $\mathbf{5 3}$ & $\mathbf{0 . 6 6}$ & 0.51 & 0.63 & $\mathbf{0 . 4 5}$ & 0.57 & 0.46 & $\mathbf{0 . 4 2}$ & 0.30 & $\mathbf{0 . 4 2}$ \\
\hline Tehran (G2) & $\mathbf{5 9}$ & $\mathbf{0 . 5 5}$ & 0.50 & 0.51 & $\mathbf{0 . 4 3}$ & 0.71 & 0.58 & $\mathbf{0 . 3 7}$ & 0.23 & 0.30 \\
\hline
\end{tabular}
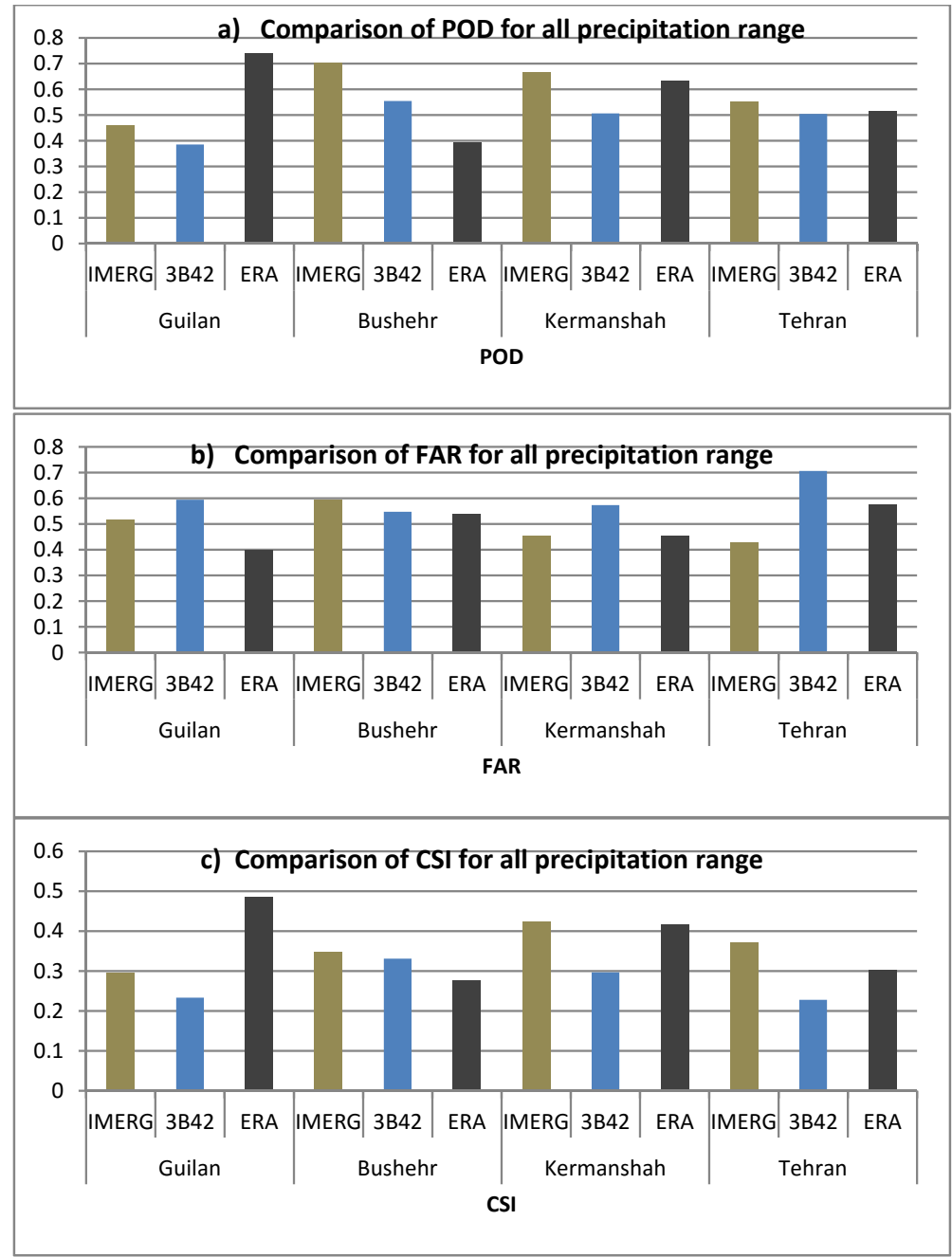

Figure 16. (a-c) POD, FAR and CSI in the four study regions.

The missed precipitation may be caused by snow cover on the ground at higher altitudes over the Alborz Mountains and by the inability to catch warm rain processes, short-lived convective storms, or maritime precipitation along the Caspian Sea. 
POD value of IMERG (0.70) seems to be better than other products over Bushehr area while it is quite low for ERA-Interim (0.39). On the other hand, IMERG indicates a high FAR value (0.59) because of rare precipitation events despite high humidity. Figure 16b shows similar results for 3B42 and ERA Interim in Bushehr area as well.

In Kermanshah area, IMERG yields a higher POD and CSI and lower FAR in comparison to 3B42. These results could be due to the inability of TRMM Microwave Imager (TMI) to measure snowfall and light rain over the ground and Zagros Mountains while the main feature of Dual-frequency Precipitation Radar (DPR) based on the GPM is to measure snowfall and light rain. Overall, the ERA-Interim product produced fewer robust results when compared to IMERG.

As Figure 16a-c and Table 16 indicate, IMERG product performs better than others with higher POD and CSI and lower FAR in Tehran. We should note that precipitation in Tehran is stratiform and orographic.

\subsubsection{Evaluation of Dichotomous Estimates/Forecasts for Precipitation below $15 \mathrm{~mm}$}

As can be seen in Figure 17a-c and Table 17, in the Guilan area, ERA-Interim performs better than IMERG and 3B42 for precipitation below $15 \mathrm{~mm}$ /day which might be due to high amount of moisture in the atmosphere in this area that the satellites observed, although precipitation did not occur. Whereas, IMERG yields better results in Tehran and Bushehr areas in comparison to the other products. Moreover, in Kermanshah, IMERG and ERA-Interim indicated rather similar behavior, while in all study areas, 3B42 indicated low values of indices for precipitation below $15 \mathrm{~mm} /$ day.

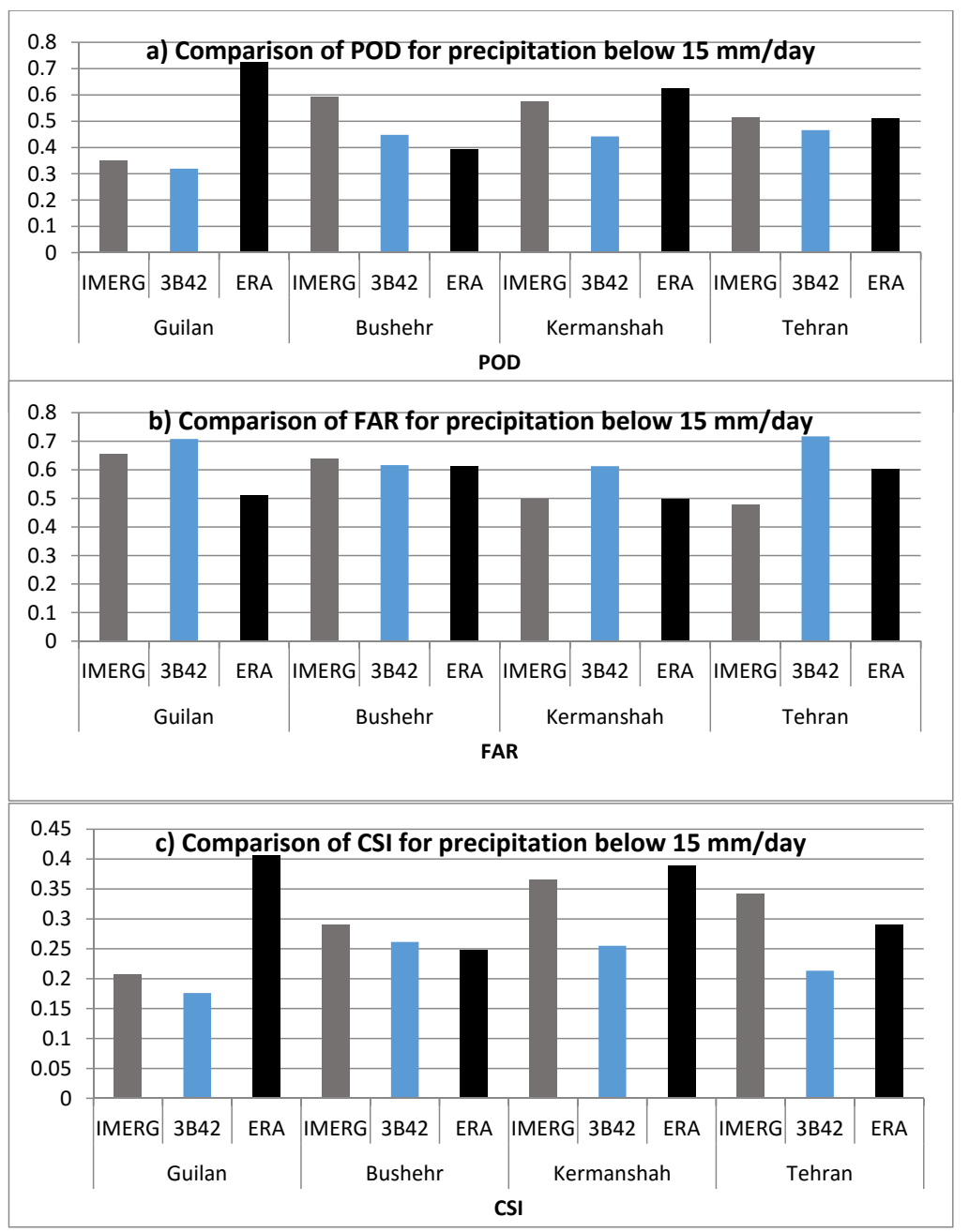

Figure 17. (a-c) POD, FAR and CSI in four study region for precipitation below $15 \mathrm{~mm} /$ day. 
Table 17. Spatially averaged POD, FAR and CSI metrics for precipitation below $15 \mathrm{~mm}$ /day.

\begin{tabular}{cccccccccccc}
\hline & & \multicolumn{3}{c}{ POD } & \multicolumn{3}{c}{ FAR } & & \multicolumn{3}{c}{ CSI } \\
\hline & $\begin{array}{c}\text { Number of } \\
\text { Precipitation } \\
\text { Days }<\mathbf{1 5} \mathbf{~ m m}\end{array}$ & IMERG & $\mathbf{3 B 4 2}$ & ERA & IMERG & $\mathbf{3 B 4 2}$ & ERA & IMERG & 3B42 & ERA \\
\hline Guilan (G8) & $\mathbf{8 5}$ & 0.35 & 0.32 & $\mathbf{0 . 7 2}$ & 0.65 & 0.71 & $\mathbf{0 . 5 1}$ & 0.21 & 0.18 & $\mathbf{0 . 4 1}$ \\
\hline Bushehr (G4) & $\mathbf{1 7}$ & $\mathbf{0 . 5 9}$ & 0.45 & 0.39 & 0.64 & 0.62 & $\mathbf{0 . 6 1}$ & $\mathbf{0 . 2 9}$ & 0.26 & 0.25 \\
\hline Kermanshah (G5) & $\mathbf{5 1}$ & 0.57 & 0.44 & $\mathbf{0 . 6 3}$ & $\mathbf{0 . 5 0}$ & 0.61 & $\mathbf{0 . 5 0}$ & 0.37 & 0.25 & $\mathbf{0 . 3 9}$ \\
\hline Tehran (G2) & $\mathbf{5 7}$ & $\mathbf{0 . 5 2}$ & 0.47 & 0.51 & $\mathbf{0 . 4 8}$ & 0.72 & 0.60 & $\mathbf{0 . 3 4}$ & 0.21 & 0.29 \\
\hline
\end{tabular}

\subsubsection{Evaluation of Dichotomous Estimates/Forecasts for Precipitation above $15 \mathrm{~mm}$}

In contrast, for precipitation above $15 \mathrm{~mm}$ /day, IMERG indicates better results for POD and CSI in all case studies while ERA-Interim indicates a very weak value (Figure 18a-c and Table 18) that could be due to KuPR (Ku-band (13.6 GHz) precipitation radar) instrument that can detect heavy precipitation.

Notice that almost in all study areas the value of FAR for precipitation above $15 \mathrm{~mm} /$ day from all products was rather high which could be due to observed liquid water in the atmosphere profiles which did not fall as precipitation due to their small size or evaporation.

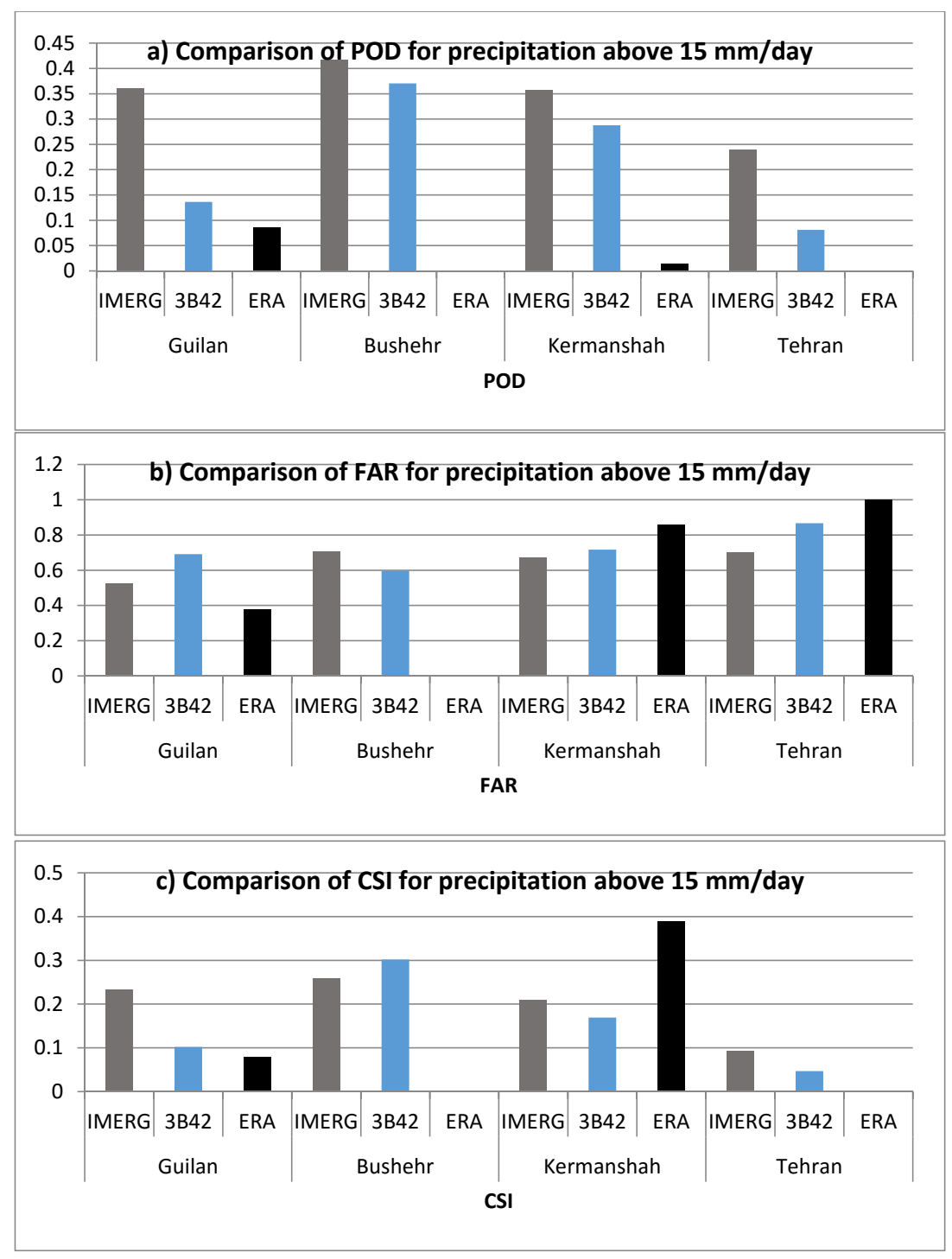

Figure 18. $(\mathbf{a}-\mathbf{c})$ POD, FAR and CSI in four study regions for precipitation above $15 \mathrm{~mm} /$ day. 
Table 18. Spatially averaged POD, FAR and CSI metrics for precipitation above $15 \mathrm{~mm}$ /day.

\begin{tabular}{cccccccccccc}
\hline & & \multicolumn{3}{c}{ POD } & & FAR & & CSI \\
\hline & $\begin{array}{c}\text { Number of } \\
\text { Precipitation } \\
\text { Days }>\mathbf{1 5} \mathbf{~ m m}\end{array}$ & IMERG & $\mathbf{3 B 4 2}$ & ERA & IMERG & $\mathbf{3 B 4 2}$ & ERA & IMERG & 3B42 & ERA \\
\hline Guilan (G8) & $\mathbf{2 0}$ & $\mathbf{0 . 3 6}$ & 0.14 & 0.09 & 0.53 & 0.69 & $\mathbf{0 . 3 8}$ & $\mathbf{0 . 2 3}$ & 0.10 & 0.08 \\
\hline Bushehr (G4) & $\mathbf{2}$ & $\mathbf{0 . 4 2}$ & 0.37 & 0.00 & 0.70 & 0.60 & - & 0.26 & $\mathbf{0 . 3 0}$ & 0.00 \\
\hline Kermanshah (G5) & $\mathbf{2}$ & $\mathbf{0 . 3 6}$ & 0.29 & 0.02 & $\mathbf{0 . 6 7}$ & 0.72 & 0.86 & 0.21 & 0.17 & $\mathbf{0 . 3 9}$ \\
\hline Tehran (G2) & $\mathbf{2}$ & $\mathbf{0 . 2 4}$ & 0.08 & 0.00 & $\mathbf{0 . 7 0}$ & 0.87 & 1.00 & $\mathbf{0 . 0 9}$ & 0.05 & 0.00 \\
\hline
\end{tabular}

\section{Conclusions}

An evaluation of the two recent post real time satellite datasets (IMERG and 3B42) and a common precipitation forecast model dataset (ERA-Interim) in daily, monthly and seasonal scales against rain-gauges for four different topography and climate conditions in Iran from mid-March 2014 to February 2015 shows that IMERG, 3B42 and ERA-Interim lead to underestimation over Iran. Overall, in daily scale (at days with observed precipitation), the results reveal that all three products lead to underestimation but IMERG underestimates precipitation slightly in all four regions. The correlation coefficient between IMERG and the rain-gauge data in daily scale is mostly far superior to those of for Era-Interim and 3B42. On the basis of daily timescale of bias in comparison with the ground data, the IMERG product is better than ERA-Interim and 3B42 products. Based on monthly and seasonal scales (all days), in Guilan (G8) all products in Bushehr (G4) and Kermanshah (G5) ERA-Interim and in Tehran (G2) IMERG and ERA-Interim tend to underestimate. According to the categorical verification technique used in this study, IMERG yields better results for detection of precipitation events on the basis of Probability of Detection (POD), Critical Success Index (CSI) and False Alarm Ratio (FAR) in those areas with stratiform and orographic precipitation such as Tehran and Kermanshah compared with other satellite/model data sets. Moreover, in case of precipitation below $15 \mathrm{~mm} /$ day, ERA-Interim and IMERG indicate better results in all study areas, particularly ERA-Interim in Guilan, which shows reasonable results of POD, FAR and CSI. Meanwhile, for heavy precipitation ( $>15 \mathrm{~mm} /$ day), IMERG is far superior to the other products in all study areas which could be used in the future for early warning of floods etc.

Relative to TRMM, GPM is designed to make more accurate and frequent observations of global precipitation, especially over middle and high latitudes [39]. Although the newly introduced sensors and upgraded calibration algorithms have undoubtedly improved the GPM constellation satellites' accuracy, some challenging issues in satellite retrieval processes will continue to remain open for the satellite community, providing the impetus for more research and development. With respect to the current monitoring skills, it is almost certain that regions characterized by complex terrain and snowy/ice cover will remain to be problematic for multi-satellite retrieval in GPM [15]. These results will better guide those users who are taking advantage of these satellite-based precipitation data to accommodate their various research and operational applications.

The following conclusions are drawn based on this study:

1. Located in North of Iran, Guilan region enjoys a humid and subtropical climate. Under this climate condition, ERA-Interim performed reasonably on the basis of POD, FAR, CSI, RMSE and MAE indices on the daily scale. Additionally, the GPM constellation satellites' product (IMERG) was superior to the TRMM Multi-satellite Precipitation Satellites (TMPA) product (3B42). Moreover, all three satellite/model products underestimated the precipitation in this region, a similar conclusion by Moazzami et al. [13] and Javanmard et al. [11] who tested 3B42 in this region. Such findings may be attributed to local wind and convective precipitation in this region so that satellites could not detect precipitation properly.

2. Along the Zagros Mountains in the West of Iran, the Kermanshah region has a hot Mediterranean subtropical climate. All products, including IMERG, TRMM and ERA-Interim, underestimate the 
precipitation on the daily scale. With respect to contingency table metrics, IMERG outperformed ERA-Interim on the basis of POD, FAR, RMSE, Bias, Mbias, Rbias and CC (correlation coefficient) while ERA-Interim performed best in terms of MAE values on the daily scale. 3B42 outperformed other products on a monthly scale. Moreover, all three products showed rather the same behavior in seasonal scale but IMERG indicates a better CC.

3. Just northwest of the Persian Gulf, Bushehr region is subject to warm and subtropical arid climate in low latitudes. In this area, on the daily scale, IMERG was more accurate in terms of Bias, Mbias, Rbias and CC while 3B42 was better in RMSE and MAE. Also, 3B42 outperformed other products on monthly and seasonal scales. On the other hand, IMERG showed reasonable results with a POD of 0.70 that could be due to the dual-frequency sensor based on the GPM which can detect light rain.

4. Tehran is located in a semi-arid climate with the towering Alborz Mountains to its North and the central desert to the South. In this region, according to the daily scale precipitation, IMERG outperformed other precipitation products with POD, FAR and CSI.

5. ERA-Interim yields weak results of POD, FAR and CSI for precipitation above $15 \mathrm{~mm} /$ day over Iran while IMERG is far superior to the other products in all study areas. ERA-Interim in Guilan region shows a significant value of POD for precipitation below $15 \mathrm{~mm} /$ day.

6. Generally, in Guilan, Kermanshah, Tehran and Bushehr regions, all three products (IMERG, 3B42 and ERA-Interim) underestimate precipitation based on daily scale, which might be due to an inadequate number of gauges which are provided by the Global Precipitation Climatology Centre (GPCC) and used for bias correction in satellite products or/and the inability to measure available water in the air profiles. Moreover, in semi-arid and hot climates, rain drops may evaporate before reaching the ground [40].

7. Based on monthly and seasonally scale, in Guilan, all products tend to underestimate while in Bushehr and Kermanshah, IMERG and 3B42, and in Tehran, 3B42 indicated overestimate.

In summary, the overestimation or underestimation over mountainous regions indicates that accurate estimation by satellite-based precipitation products remains a challenge. Such inaccuracy may be rooted in the inadequate number of gauges, provided by the Global Precipitation Climatology Centre (GPCC) and used for bias correction in satellite products or the non-uniform beam filling (NUBF) problem for remote sensing instruments. Another cause might be the spatial resolution of the satellite product, since precipitation within a region may occur in smaller scales than the pixel size of satellites. Overall, this preliminary accuracy assessment highlights that the IMERG product can adequately substitute 3B42 products despite its limited historic record. As more IMERG data become available, more detailed studies of GPM-IMERG applications in water, weather, and climate studies are possible in the near future. We expect that the regional analysis of GPM constellation satellites-based precipitation estimates reported here can give the satellite precipitation users a better understanding of the features associated with currently available IMERG precipitation estimates from a broader perspective.

Supplementary Materials: The following are available online at www.mdpi.com/2072-4292/8/2/135, Figure S1, Tables S1 and S2.

Acknowledgments: The 3B42 and IMERG data were provided by the NASA/Goddard Space Flight Center's and PPS, which develop and compute the 3B42 and IMERG as a contribution to TMPA and GPM constellation satellites, and archived at the NASA GES DISC. We acknowledge the ECMWF-ERA-Interim datasets from the Meteorological Archiving System (MARS) of the European Centre for Medium Range Weather Forecasts (ECMWF). We acknowledge the mission scientists and Principal Investigators who provided the data used in this research effort.

Author Contributions: Reinhold Steinacker and Bahram Saghafian designed the framework of this study, edited the manuscript and contributed as supervisors and Ehsan Sharifi provided data, analyzed and wrote the manuscript. All authors discussed the results and implications on the manuscript at all stages.

Conflicts of Interest: The authors declare no conflict of interest. 


\section{References}

1. AghaKouchak, A.; Nasrollahi, N.; Li, J.; Imam, B.; Sorooshian, S. Geometrical characterization of precipitation patterns. J. Hydrometeorol. 2011, 12, 274-285. [CrossRef]

2. AghaKouchak, A.; Mehran, A.; Norouzi, H.; Behrangi, A. Systematic and random error components in satellite precipitation data sets. Geophys. Res. Lett. 2012, 39. [CrossRef]

3. Amitai, E.; Llort, X.; Sempere-Torres, D. Comparison of TRMM radar rainfall estimates with NOAA next-generation QPE. J. Meteorol. Soc. Jpn. 2009, 87A, 109-118. [CrossRef]

4. De Coning, E. Optimizing satellite-based precipitation estimation for nowcasting of rainfall and flash flood events over the South African domain. Remote Sens. 2013, 5, 5702-5724. [CrossRef]

5. De Coning, E.; Poolman, E. South African Weather Service operational satellite based precipitation estimation technique: Applications and improvements. Hydrol. Earth Syst. Sci. 2011, 15, 1131-1145. [CrossRef]

6. Huffman, G.J.; Bolvin, D.T.; Braithwaite, D.; Hsu, K.; Joyce, R. Algorithm Theoretical Basis Document (ATBD) Version 4.5: NASA Global Precipitation Measurement (GPM) Integrated Multi-satellitE Retrievals for GPM (IMERG); NASA: Greenbelt, MD, USA, 2015.

7. Huffman, G.J.; Bolvin, D.T.; Nelkin, E.J. Day 1 IMERG Final Run Release Notes; NASA Goddard Earth Sciences Data and Information Services Center: Greenbelt, MD, USA, 2015.

8. Dee, D.P.; Uppala, S.M.; Simmons, A.J.; Berrisford, P.; Poli, P.; Kobayashi, S.; Andrae, U.; Balmaseda, M.A.; Balsamo, G.; Bauer, P.; et al. The ERA-Interim reanalysis: Configuration and performance of the data assimilation system. Q. J. R. Meteorol. Soc. 2011, 137, 553-597. [CrossRef]

9. Ashouri, H.; Hsu, K.-L.; Sorooshian, S.; Braithwaite, D.K.; Knapp, K.R.; Cecil, L.D.; Nelson, B.R.; Prat, O.P. PERSIANN-CDR: Daily precipitation climate data record from multisatellite observations for hydrological and climate studies. Bull. Am. Meteorol. Soc. 2015, 96, 69-83. [CrossRef]

10. Bao, X.; Zhang, F. Evaluation of NCEP-CFSR, NCEP-NCAR, ERA-Interim, and ERA-40 Reanalysis Datasets against independent sounding observations over the Tibetan Plateau. J. Clim. 2013, 26, 206-214. [CrossRef]

11. Javanmard, S.; Yatagai, A.; Nodzu, M.I.; BodaghJamali, J.; Kawamoto, H. Comparing high-resolution gridded precipitation data with satellite rainfall estimates of TRMM_3B42 over Iran. Adv. Geosci. 2010, 25, 119-125. [CrossRef]

12. Moazami, S.; Golian, S.; Kavianpour, M.R.; Hong, Y. Comparison of PERSIANN and V7 TRMM Multi-satellite Precipitation Analysis (TMPA) products with rain gauge data over Iran. Int. J. Remote Sens. 2013, 34, 8156-8171. [CrossRef]

13. Moazami, S.; Golian, S.; Hong, Y.; Sheng, C.; Kavianpour, M.R. Comprehensive evaluation of four high-resolution satellite precipitation products over diverse climate conditions in Iran. Hydrol. Sci. J. 2015. [CrossRef]

14. Tobin, K.J.; Bennett, M.E. Adjusting satellite precipitation data to facilitate hydrologic modeling. J. Hydrometeorol. 2010, 11, 966-978. [CrossRef]

15. Yong, B.; Liu, D.; Gourley, J.J.; Tian, Y.; Huffman, G.J.; Ren, L.; Hong, Y. Global view of real-time TRMM multisatellite precipitation analysis: Implications for its successor global precipitation measurement mission. Bull. Am. Meteorol. Soc. 2015, 96, 283-296. [CrossRef]

16. Bowman, K.P. Comparison of TRMM precipitation retrievals with rain gauge data from ocean buoys. J. Clim. 2005, 18, 178-190. [CrossRef]

17. Pan, M.; Wood, E.F. Impact of accuracy, spatial availability, and revisit time of satellite-derived surface soil moisture in a multiscale ensemble data assimilation system. IEEE J. Sel. Top. Appl. Earth Obs. Remote Sens. 2010, 3, 49-56. [CrossRef]

18. Bell, T.L. Comparing satellite rainfall estimates with rain gauge data: Optimal strategies suggested by a spectral model. J. Geophys. Res. 2003, 108. [CrossRef]

19. New, M.; Hulme, M.; Jones, P. Representing twentieth-century space-time climate variability: Part I: Development of a 1961-90 mean monthly terrestrial climatology. J. Clim. 1999, 12, 829-856. [CrossRef]

20. Mitchell, T.D.; Jones, P.D. An improved method of constructing a database of monthly climate observations and associated high-resolution grids. Int. J. Climatol. 2005, 25, 693-712. [CrossRef]

21. Schneider, U.; Ziese, M.; Becker, A.; Meyer-Christoffer, A.; Finger, P. Global Precipitation Analysis Products of the GPCC; Global Precipitation Climatology Centre (GPCC), Deutscher Wetterdienst: Offenbach, Germany, 2015. 
22. Yatagai, A.; Xie, P.; Alpert, P. Development of a daily gridded precipitation data set for the Middle East. Adv. Geosci. 2008, 12, 165-170. [CrossRef]

23. Yatagai, A.; Arakawa, O.; Kamiguchi, K.; Kawamoto, H.; Nodzu, M.I.; Hamada, A. 44 year daily gridded precipitation dataset for Asia based on a dense network of rain gauges. Sci. Online Lett. Atmos. 2009, 5, 137-140. [CrossRef]

24. Xie, P.; Chen, M.; Yang, S.; Yatagai, A.; Hayasaka, T.; Fukushima, Y.; Liu, C. A gauge-based analysis of daily precipitation over East Asia. J. Hydrometeorol. 2007, 8, 607-626. [CrossRef]

25. Renzullo, L.; Chappell, A.; Raupach, T.; Dyce, P.; Li, M.; Shao, Q. An Assessment of Statistically Blended Satellite-Gauge Precipitation Data for Daily Rainfall Analysis in Australia. In Proceedings of the 34th International Symposium on Remote Sensing of Environment (ISRSE), Sydney, Australia, 10-15 April 2011.

26. Hazarika, M.K.; Kafle, T.P.; Sharma, R.; Karki, S.; Shrestha, R.M.; Samarkoon, L. Statistical approach to discharge prediction for flood forecasts using TRMM data. In Proceedings of the 5th Annual Mekong Flood Forum, Ho Chi Minh City, Vietnam, 17-18 May 2007.

27. Su, F.; Hong, Y.; Lettenmaier, D.P. Evaluation of TRMM Multisatellite Precipitation Analysis (TMPA) and its utility in hydrologic prediction in the La Plata Basin. J. Hydrometeorol. 2008, 9, 622-640. [CrossRef]

28. Fleming, K.; Awange, J.L.; Kuhn, M.; Featherstone, W.E. Evaluating the TRMM 3B43 monthly precipitation product using gridded raingauge data over Australia. Aust. Meteorol. Oceanogr. J. 2011, 61, 171-184.

29. Huffman, G.J.; Bolvin, D.T.; Nelkin, E.J.; Wolff, D.B.; Adler, R.F.; Gu, G.; Hong, Y.; Bowman, K.P.; Stocker, E.F. The TRMM Multisatellite Precipitation Analysis (TMPA): Quasi-Global, multiyear, combined-sensor precipitation estimates at fine scales. J. Hydrometeorol. 2007, 8, 38-55. [CrossRef]

30. Chiodo, G.; Haimberger, L. Interannual changes in mass consistent energy budgets from ERA-Interim and satellite data. J. Geophys. Res. 2010, 115, D2. [CrossRef]

31. Modarres, R. Regional precipitation climates of Iran. J. Hydrol. (NZ) 2006, 45, 13-27.

32. Fisher, W.B. The Cambridge History of Iran: Climate; Cambridge University Press: Cambridge, UK, 1968.

33. NASA. “GPM_3IMERGHH 03”. Available online: http://disc.sci.gsfc.nasa.gov/SSW/ (accessed on 6 June 2015).

34. European Centre for Medium-Range Weather Forecasts (ECMWF). "ERA Interim, Daily". Available online: http://apps.ecmwf.int/datasets/data/interim-full-daily/ (accessed on 1 July 2015).

35. Ebert, E.E.; Janowiak, J.E.; Kidd, C. Comparison of near-real-time precipitation estimates from satellite observations and numerical models. Bull. Am. Meteorol. Soc. 2007, 88, 47-64. [CrossRef]

36. Thornes, J.E.; Stephenson, D.B. How to judge the quality and value of weather forecast products. Meteorol. Appl. 2001, 8, 307-314. [CrossRef]

37. Wilks, D.S. Statistical Methods in the Atmospheric Sciences; Elsevier: New York, NY, USA, 2006.

38. Nasrollahi, N. False alarm in satellite precipitation data. In Improving Infrared-Based Precipitation Retrieval Algorithms Using Multi-Spectral Satellite Imagery; Nasrollahi, N., Ed.; Springer International Publishing: Cham, Germany, 2015; pp. 7-12.

39. Hou, A.Y.; Kakar, R.K.; Neeck, S.; Azarbarzin, A.A.; Kummerow, C.D.; Kojima, M.; Oki, R.; Nakamura, K.; Iguchi, T. The global precipitation measurement mission. Bull. Am. Meteorol. Soc. 2014, 95, 701-722. [CrossRef]

40. Tesfagiorgis, K.; Mahani, S.E.; Krakauer, N.Y.; Khanbilvardi, R. Bias correction of satellite rainfall estimates using a radar-gauge product-A case study in Oklahoma (USA). Hydrol. Earth Syst. Sci. 2011, 15, 2631-2647. [CrossRef]

(C) 2016 by the authors; licensee MDPI, Basel, Switzerland. This article is an open access article distributed under the terms and conditions of the Creative Commons by Attribution (CC-BY) license (http://creativecommons.org/licenses/by/4.0/). 